System-Wide Water Resources Program (SWWRP)

\title{
Using a Multi-Scale Assessment of Watershed Integrity (MAWI) Approach for Establishing Baseline Conditions in Watersheds
}

Jeff P. Lin, Ronald D. Smith, and Barbara A. Kleiss

April 2008

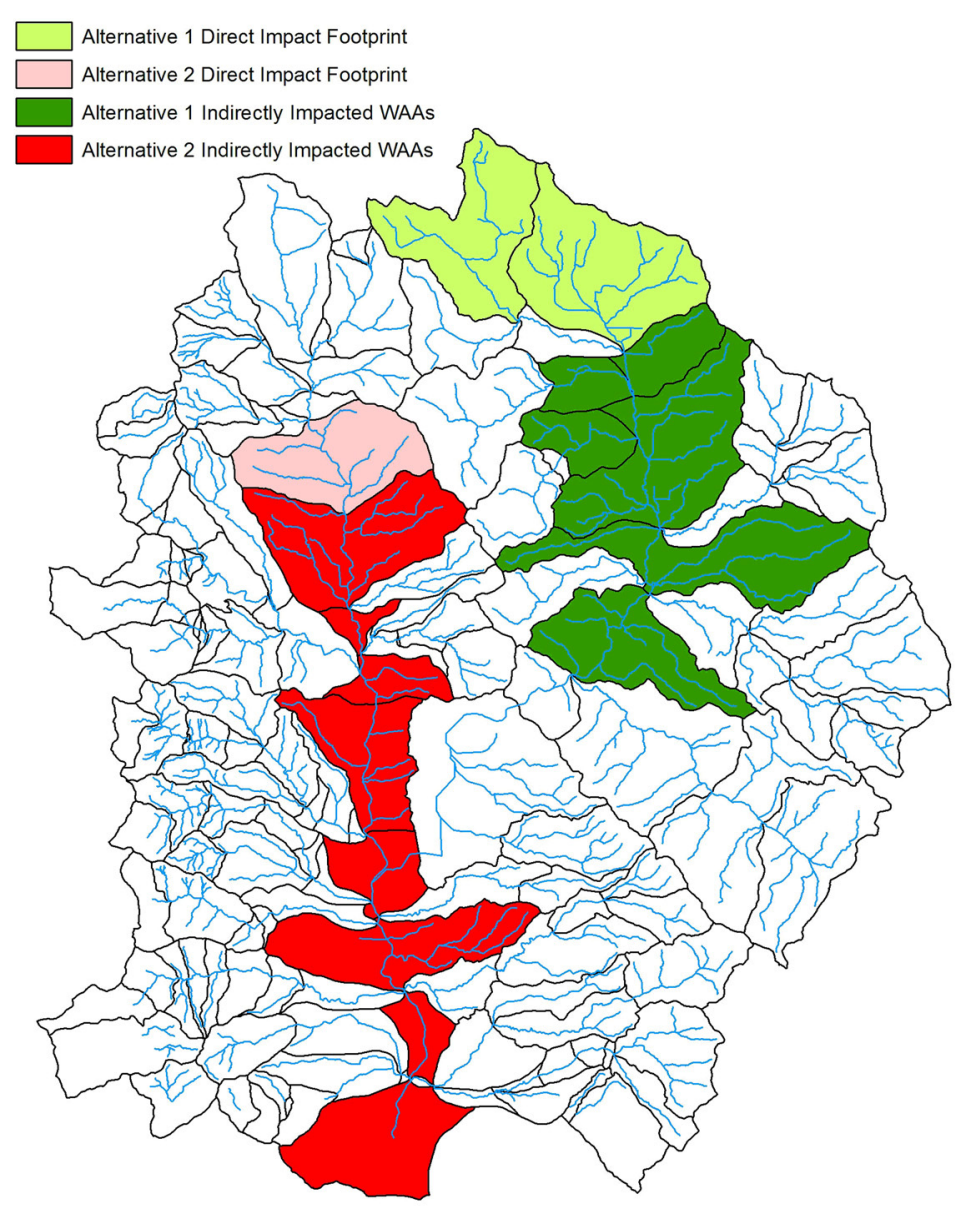

Approved for public release; distribution is unlimited. 


\section{Using a Multi-Scale Assessment of Watershed Integrity (MAWI) Approach for Establishing Baseline Conditions in Watersheds}

Jeff P. Lin, Ronald D. Smith, and Barbara A. Kleiss

Environmental Laboratory

U.S. Army Engineer Research and Development Center

3909 Halls Ferry Road

Vicksburg, MS 39180-6199

Final report

Approved for public release; distribution is unlimited. 


\begin{abstract}
This report describes the development and application of an updated version of the Multi-Scale Assessment of Watershed Integrity (MAWI) approach for watershed assessment. This work demonstrated the approach's capabilities as an assessment and planning tool using parts of the MAWI model developed for the Russian River watershed in northern California. The report also discusses the possibility of adapting the Russian River MAWI model for use in watersheds nationally.
\end{abstract}

DISCLAIMER: The contents of this report are not to be used for advertising, publication, or promotional purposes. Citation of trade names does not constitute an official endorsement or approval of the use of such commercial products. All product names and trademarks cited are the property of their respective owners. The findings of this report are not to be construed as an official Department of the Army position unless so designated by other authorized documents. 


\section{Contents}

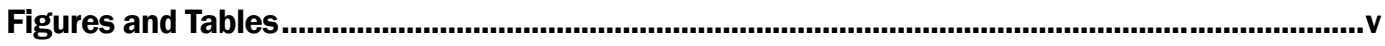

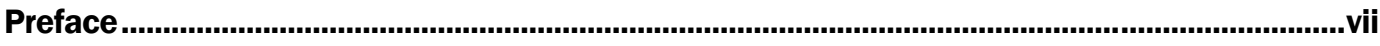

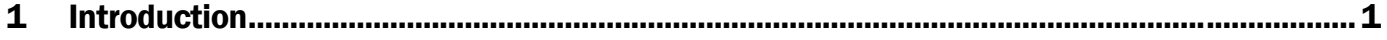

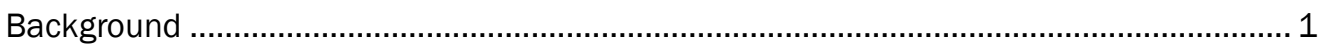

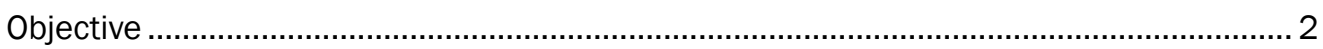

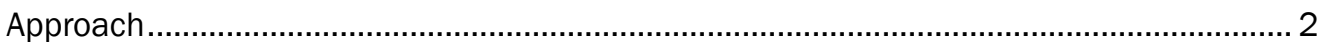

Scope

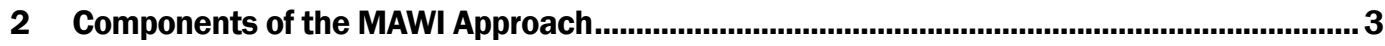

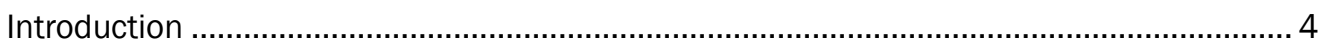

Collecting existing information and data ................................................................... 5

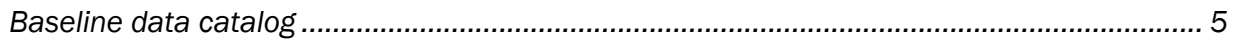

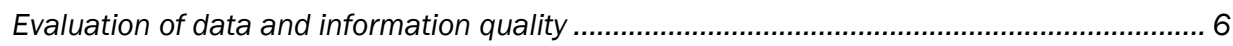

Delineating watershed assessment areas ................................................................... 7

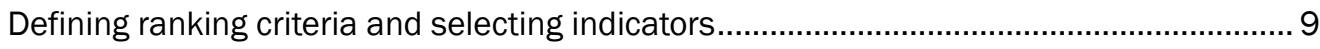

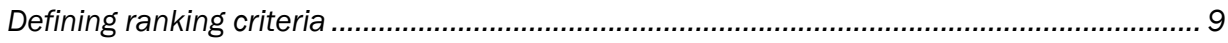

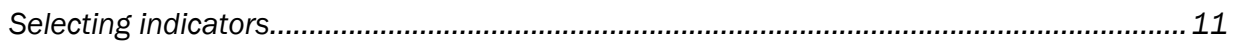

Develop a knowledge base using indicators and criteria................................................. 12

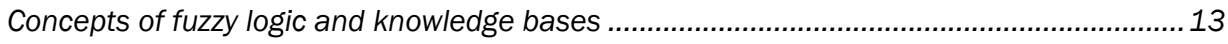

Incorporating NetWeaver into the MAWI approach............................................................. 14

Structure of a NetWeaver knowledge base ..................................................................... 15

Determining truth values in the NetWeaver knowledge base ............................................. 16

Use the knowledge base to assess WAAs in terms of criteria ........................................ 21

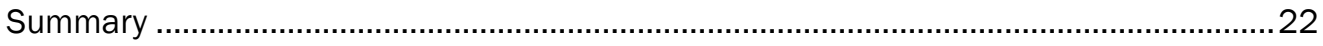

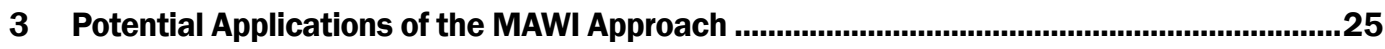

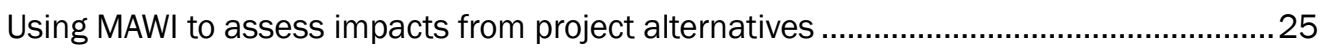

Using MAWI to prioritize restoration and conservation options........................................28

Developing a nationwide MAWI knowledge base .............................................................28

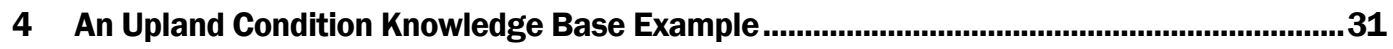

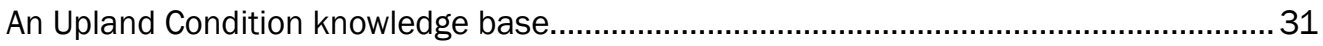

Upland Condition (primary criterion) - overview........................................................... 31

Vegetation Condition (secondary criterion) - overview ....................................................32

Presence of Native Vegetation Communities (indicator) - overview ..................................... 33

Fire Regime Condition Class (indicator)........................................................................ 34

Fauna Condition (secondary criterion) - overview........................................................... 36

Percent of potential amphibian richness, percent of potential reptile richness,

percent of potential mammal richness, percent of potential bird richness

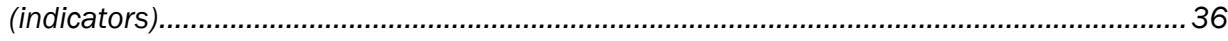

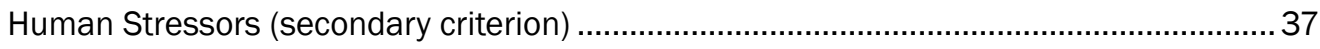

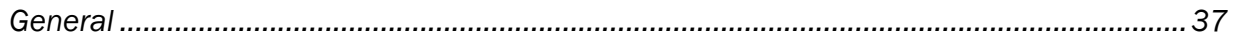


Landscape Development Intensity (LDI) index (indicator) ................................................. 38

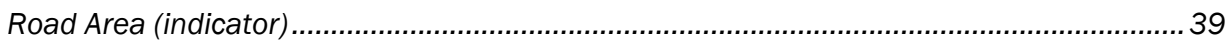

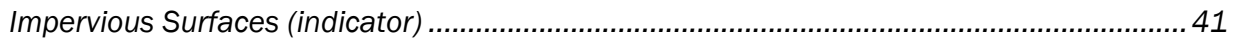

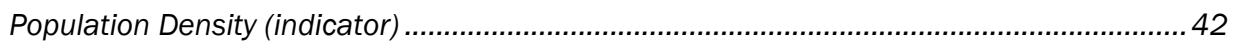

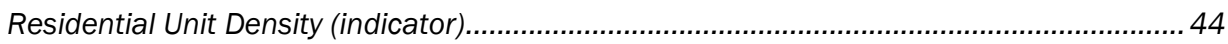

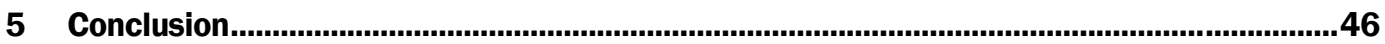

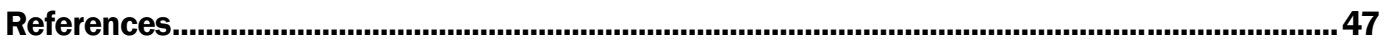

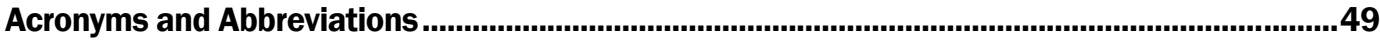

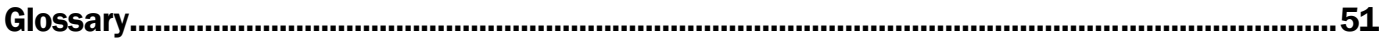

Report Documentation Page 


\section{Figures and Tables}

\section{Figures}

Figure 1. WAAs, local drainages, drainage basins, and stream, riparian, and upland components of the WAA.

Figure 2. Fuzzy curve showing the relationship between tree basal area and truth value.............. 14

Figure 3. A primary criterion set up in NetWeaver............................................................................ 15

Figure 4. Fire Regime criterion set up in NetWeaver, containing only one data input..................... 17

Figure 5. Human disturbance criterion set up in NetWeaver, containing multiple data inputs.

Figure 6. Habitat Quality criterion set up in NetWeaver, composed of multiple criteria..

Figure 7. On the left is the Vegetation Condition criterion set up in NetWeaver, composed of two criteria.

Figure 8. Literature-derived relationship between truth value Fire Regime Condition Class Indicator.

Figure 9. Intuitively derived relationship between truth value and Native Vegetation Communities indicator.

Figure 10. Empirically derived relationship between truth value and data input for Population Density indicator......

Figure 11. An EMDS map output, showing categorized truth values for an Upland Condition criterion in individual WAAs in the Russian River Watershed, located in northern California.

Figure 12. An example of tabular output created in EMDS, which shows the truth values for all indicators and criteria.....

Figure 13. Comparison of WAAs directly and indirectly impacted by two hypothetical project alternatives in a selected portion of the Russian River watershed.

Figure 14. Decreases in truth value to a condition criterion in individual WAAs as a result of impacts from two hypothetical project alternatives in a selected portion of the Russian River watershed.

Figure 15. Hypothetical categorized truth values of individual WAAs for a restoration potential criterion in a selected portion of the Russian River watershed.

Figure 16. Overview schematic of the Upland Condition knowledge base.

Figure 17. Relationship between truth value and data input for Native Vegetation Communities indicator.

Figure 18. Relationship between truth value and data input for Fire Regime Condition Class indicator.

Figure 19. Relationship between truth value and data input for potential species group (amphibian, reptile, mammal, bird) richness indicator.

Figure 20. Relationship between truth value and data input for Landscape Development Intensity Index indicator.

Figure 21. Relationship between truth value and data input for the Road Area indicator.

Figure 22. Relationship between truth value and data input for Impervious Surfaces indicator. 
Figure 23. Relationship between truth value and data input for Population Density indicator.

Figure 24. Relationship between truth values and data input for Residential Unit Density indicator..

\section{Tables}

Table 1. General baseline data catalog information categories and descriptions. ............................ 6

Table 2. LDI coefficients for various land uses............................................................................ 39 


\section{Preface}

This work was completed under funding from the System-Wide Water Resources Program (SWWRP). Dr. Steven L. Ashby is Program Manager of SWWRP. This work took place under the general supervision of Dr. Morris Mauney, Jr., Chief, Wetlands and Coastal Ecology Branch, Environmental Laboratory (EL), U.S. Army Engineer Research and Development Center (ERDC), Vicksburg, MS.

This report was prepared by Jeff P. Lin, Ronald D. Smith, and Barbara A. Kleiss, Wetlands and Coastal Ecology Branch, EL, ERDC. At the time of publication of this report, Dr. Beth Fleming was Director of EL.

COL Richard B. Jenkins is Commander and Executive Director of ERDC. Dr. James R. Houston is Director. 


\section{Introduction}

\section{Background}

There is a growing need to incorporate consideration of off-site and cumulative impacts when evaluating the effects of land use and development activities (Reid 1998). This sort of analysis is particularly important for water-resource related projects, where the interconnectivity of various water bodies and their associated riparian and upland areas can cause changes in one localized area to affect the rest of the watershed. Because of these considerations, the U.S. Army Corps of Engineers' Civil Works program has adopted a watershed perspective for water resources development, protection, and management (Headquarters, U.S. Army Corps of Engineers (USACE) 2004). A watershed perspective promotes consideration of the linkages among landscape components, such as the effects of land use on stream water quality and discharge, or the potential influence of water diversions or storage on the habitat quality of downstream channels, wetlands, and riparian areas.

The U.S. Army Engineer Research and Development Center (ERDC) addressed the need for a watershed assessment tool by developing the Multi-scale Assessment of Watershed Integrity (MAWI) approach. MAWI was originally developed for use by the U.S. Army Engineer District, Los Angeles to apply to five watersheds in three southern California counties, in the context of a Special Area Management Plan (Smith et al. 2005). MAWI was later substantially modified for application to the Russian River watershed in northern California. The current version of MAWI is a tool for assessing the integrity of ecosystems (i.e., upland, riparian, stream) within discrete assessment units of a watershed, using both field and computer-generated data from multiple spatial scales, and making extensive use of desktop Geographic Information Systems (GIS) software. Assessments are based on fuzzy logic models that formally specify empirical relationships between indicators to provide an estimate of ecosystem integrity relative to a reference condition.

MAWI is designed for use in projects that encompass large spatial scales (i.e., watersheds) where heuristic approaches and relative measures can satisfy project requirements, and where the time, resources, or data required to deploy mechanistic process models are unavailable. MAWI can 
be used to assess baseline conditions, measure project-specific or cumulative impacts, compare alternatives, identify locations within a watershed that meet specific management, restoration, or conservation criteria, design restoration templates, or provide focus areas for more detailed research and data collection.

\section{Objective}

The objective of this report is to describe the development and application of an updated version of MAWI.

\section{Approach}

This programming effort substantially modified MAWI for application to the Russian River watershed in northern California.

\section{Scope}

MAWI is not a rigid model or set of indicators, but rather a flexible, general framework from which to approach watershed-scale assessments. Parts of the system developed for the Russian River are used to demonstrate the capabilities of MAWI as an assessment and planning tool. Finally, the possibility of adapting the Russian River MAWI model for use in watersheds nationally is discussed. 


\section{Components of the MAWI Approach}

The overall objective of a watershed assessment is to describe watershed conditions in a context that can be used for impact analysis, development of effective mitigation and restoration plans, recognition of key areas for protection, and similar applications. MAWI approaches that objective by characterizing the condition and functionality of key ecosystem components that can be evaluated across a range of spatial scales. The original iterations of MAWI focused on riparian areas as integrators of overall ecosystem function, and the key components were represented by Hydrologic, Water Quality, and Habitat Integrity Indices. The values calculated for each index were derived from a set of factors (called indicators) that could be evaluated in the field or from existing spatial datasets.

For example, the Habitat Integrity Index was the product of an equation combining values for a set of indicators reflecting vegetation condition, spatial arrangement of habitat units, and similar considerations. Each Integrity Index was calculated for each of many subwatersheds, which allowed comparisons to be made between individual small units, or alternatively, which allowed the scores to be aggregated among two or more units to allow comparisons at broader scales. Most importantly, some of the indicators used to assess individual subwatersheds were dependent on conditions in other subwatersheds up- or downstream. Because of that interdependence, any change (impact, restoration, etc.) postulated for any particular subwatershed could have implications for the rest of the watershed as a whole. The newer version of MAWI retains these basic concepts, but expands the focus beyond the riparian zone to include upland and instream assessments, adopts a different approach to the way indicators are combined into overall integrity indices, and employs specialized software to expand the utility and flexibility of the assessment.

The principal product of MAWI is the initial Baseline Watershed Assessment, which characterizes current conditions of the watershed. By postulating certain potential actions (impacts, restoration projects, etc.), running a new assessment, and then comparing the results to the baseline assessment, planners and resource managers can recognize and quantify the extent to which a particular action will have an adverse or positive 
effect across multiple scales. Factoring in costs allows comparisons among alternative actions in terms of efficiency. These and similar applications of MAWI allow resource agencies and other users to develop detailed watershed management plans, conduct regulatory programs, evaluate development proposals, and conduct other complex, multi-resource planning efforts.

A watershed assessment tool capable of this range of applications must incorporate certain specific components that support rapid scenariotesting in a GIS environment and clear, informative display capabilities. The current version of MAWI incorporates those characteristics by following a specific series of steps during development of the Baseline Watershed Assessment, specifically, by:

1. Collecting Existing Information and Data

2. Delineating Watershed Assessment Areas (WAAs)

3. Defining Ranking Criteria and Selecting Indicators

4. Developing Knowledge Bases using Indicators and Criteria

5. Using Knowledge Base to Assess WAAs in Terms of Criteria.

The following chapters describe the steps listed above as they are implemented in the current version of MAWI.

\section{Introduction}

A watershed assessment approach that takes advantage of existing data can be assembled and applied much more efficiently than one requiring extensive data development. Therefore an important first step in constructing a baseline watershed assessment is the compilation and organization of existing information. Data can come from a variety of sources. A good place to start searching for spatial data is through publicly accessible, web-based local, state, or national GIS databases. Ideally, the information collected should be organized in a format so that data can be easily stored, accessed, sorted, cross-referenced, updated, analyzed, used in assessing ranking criteria, and otherwise used efficiently throughout the entire assessment process, essentially creating a "data catalog." The suggested format for a data catalog is as a series of spreadsheets. A spreadsheet format is optimal for two primary reasons. First, spreadsheet software is widely available, standardized, and familiar to most potential end users. Second, data and information can be easily entered or imported into spreadsheets and subsequently updated, manipulated, sorted, queried, 
shared, or exported to a GIS. A dedicated database format is not considered appropriate for this earlier stage because of the dynamic nature of the initial compilation process, and also because of the fact that database software is not as widely available or standardized, and that fewer potential end users are fluent in the use of databases. However, as the structure and content of the data catalog stabilize, the data and information contained in the catalog could easily be transferred to a dedicated database if desired.

\section{Collecting existing information and data}

\section{Baseline data catalog}

This section presents information on the baseline data catalog created for the application of MAWI to the Russian River watershed in Northern California. The structure of this catalog can be used as a template or guide for organizing baseline data in other watersheds.

The Russian River baseline data catalog (RRBDC) consists of three spreadsheets. RRBDC Spreadsheet 1 contains information on spatial datasets, RRBDC Spreadsheet 2 contains actual spatial data values, and RRBDC Spreadsheet 3 contains citations and hyperlinks to a variety of literature, reports, data, and other information relevant to Baseline Watershed Assessment and other related tasks. Spreadsheet 1 of the RRBDC consists of two worksheets. The first worksheet, with a tab labeled "Metadata," describes each of the categories of information that is available for each spatial dataset. Table 1 lists the categories that would be generally applicable to other studies. Status Acquisition/Development (Category 1) refers to the status of the spatial dataset. Classes in this category included:

- Acquired (i.e., data downloaded from source and displayed in a GIS with no problem)

- Developed (i.e., data developed independently)

- Redundant (i.e., data downloaded and displayed with no problems, but data is redundant with other information)

- Not Applicable (data downloaded and displayed with no problem, but data is probably of little practical use)

- Unavailable (data could not be acquired from the source for various reasons)

- Corrupt Source (data downloaded from source was corrupt), and

- Data Gap (no source of data located). 
Table 1. General baseline data catalog information categories and descriptions.

\begin{tabular}{|l|l|}
\hline $\begin{array}{l}\text { Information } \\
\text { Category }\end{array}$ & Description \\
\hline 1 & $\begin{array}{l}\text { Status Acquisition/Development (Classes: Acquired, Developed, Redundant, } \\
\text { Not Applicable, Unavailable, Corrupt Source, and Data Gap) }\end{array}$ \\
\hline 2 & Source \\
\hline 3 & Data and Information Element Number \\
\hline 4 & Description of Data or Information \\
\hline 5 & $\begin{array}{l}\text { Data Quality Category (Classes: Acceptable (A), Questionable (Q), } \\
\text { Unacceptable (U), Not Rated (NR), To Be Determined (TBD) }\end{array}$ \\
\hline 6 & Indicator Association \\
\hline 7 & Metadata Hyperlink \\
\hline 8 & Data Hyperlink \\
\hline
\end{tabular}

Category 5, Data Quality, is explained in more detail in the "Evaluation of Data and Information Quality" section of this chapter (below). The Indicator Association (Category 6) identifies the knowledge base indicator associated with the spatial data. The second worksheet in RRBDC Spreadsheet 1 contains the actual categories for each spatial dataset. The descriptions of the other information categories are largely self-explanatory.

Spreadsheet 2 of the RRBDC consists of a single worksheet that contains the values of each spatial dataset arranged alphabetically by watershed assessment unit codes. Spreadsheet 3 of the RRBDC consists of a single worksheet that contains citations and links to a variety of literature, reports, data, and other information. Each item in Spreadsheet 4 is assigned to a general topic category and then given a short description of content, unique identification code, hard drive folder location of the file, electronic document status, hardcopy status, hyperlink, and citation.

\section{Evaluation of data and information quality}

The data and information collected should be evaluated in terms of its quality. The evaluation of quality is a subjective process, and meaningful only in the context of its intended use. For example, data that is considered inappropriate for use at a small spatial scale might be appropriate for use at a large spatial scale. For the RRBDC, each data and information element was assigned to a Data Quality Category of Acceptable (A), Questionable (Q), Unacceptable (U), Not Rated (NR), or To Be Determined (TBD). Data classified into the questionable, not acceptable, and unknown categories were accompanied with an explanation for why the 
data were not classified as acceptable. Spatial data quality was evaluated by reviewing available metadata to determine whether or not it was complete and within an acceptable range of positional accuracy (e.g., RMSE values). Non-spatial data quality was evaluated by determining whether or not the accuracy and/or resolution were appropriate for the intended use. When possible, the evaluation of non-spatial data was based on statements made by authors of the data. When the authors provided no information, a preliminary, subjective determination of data quality was made based on professional knowledge and expertise.

\section{Delineating watershed assessment areas}

A method was developed to delineate the different areas of a watershed, to assess and rank different areas within it at an appropriate spatial scale. These distinct areas are referred to in MAWI as WAAs. Several factors are considered in establishing WAAs. Ideally, assessment areas have a low level of heterogeneity in terms of vegetation, land use, geology, geomorphology, and stream characteristics. Assessment areas with a high level of heterogeneity can be influenced by an "averaging effect," in which assessment results tend towards a mean value. For example, if an assessment area consists of half mature forest with a "high" ecological value (i.e., natural condition) and half of agricultural lands with a "low" ecological value (i.e., altered conditions), the overall assessment will tend toward an average value that can mask the fact that the mature forest portion of the area is possibly vulnerable, or a candidate for conservation, while the agricultural portion of the area may be a candidate for restoration. Although it is not possible to completely eliminate the "averaging effect," it can be minimized by dividing the watershed into smaller WAAs through the judicious placement of WAA boundaries while considering vegetation, land use, geology, geomorphology, and stream characteristics. The ability to minimize the "averaging effect" depends to a large extent on the time and resources available to delineate smaller WAA and manually adjust WAA boundaries (Jarvinen 1985), as well as the spatial resolution of the data used to distinguish WAA boundaries.

WAAs are initially delineated based on U.S. Geological Survey (USGS) 7.5-minute quadrangles, using a second order Strahler (1957) stream channel "rule of thumb," as follows: 
- Moving downstream from the origin of a headwater stream channel, a downstream boundary point was established for a WAA where the selected second order stream joined another second order stream.

- Moving downstream, additional WAA downstream boundaries were established at: (1) the confluence with other second order or larger streams, or (2) where significant geologic, geomorphic, or land use/land cover changes occurred.

- The topographic drainage basin defined by the downstream boundary point of each WAA was then digitized based on the contours on the USGS 7.5-minute quadrangle. For example, the point where the second order streams Hulbert_06TC and Hulbert_o6TB join defines the downstream WAA boundary for the Hulbert_o6TC and Hulbert_o6TB WAAs (Figure 1). Further downstream the Hulbert_o6TA joins Hulbert_07 to define a downstream WAA boundary for Hulbert_o6TA and Hulbert_07 WAAs. The downstream WAA boundary for Hulbert_12 was not based on stream order, but rather on a change in land use or stream characteristic.

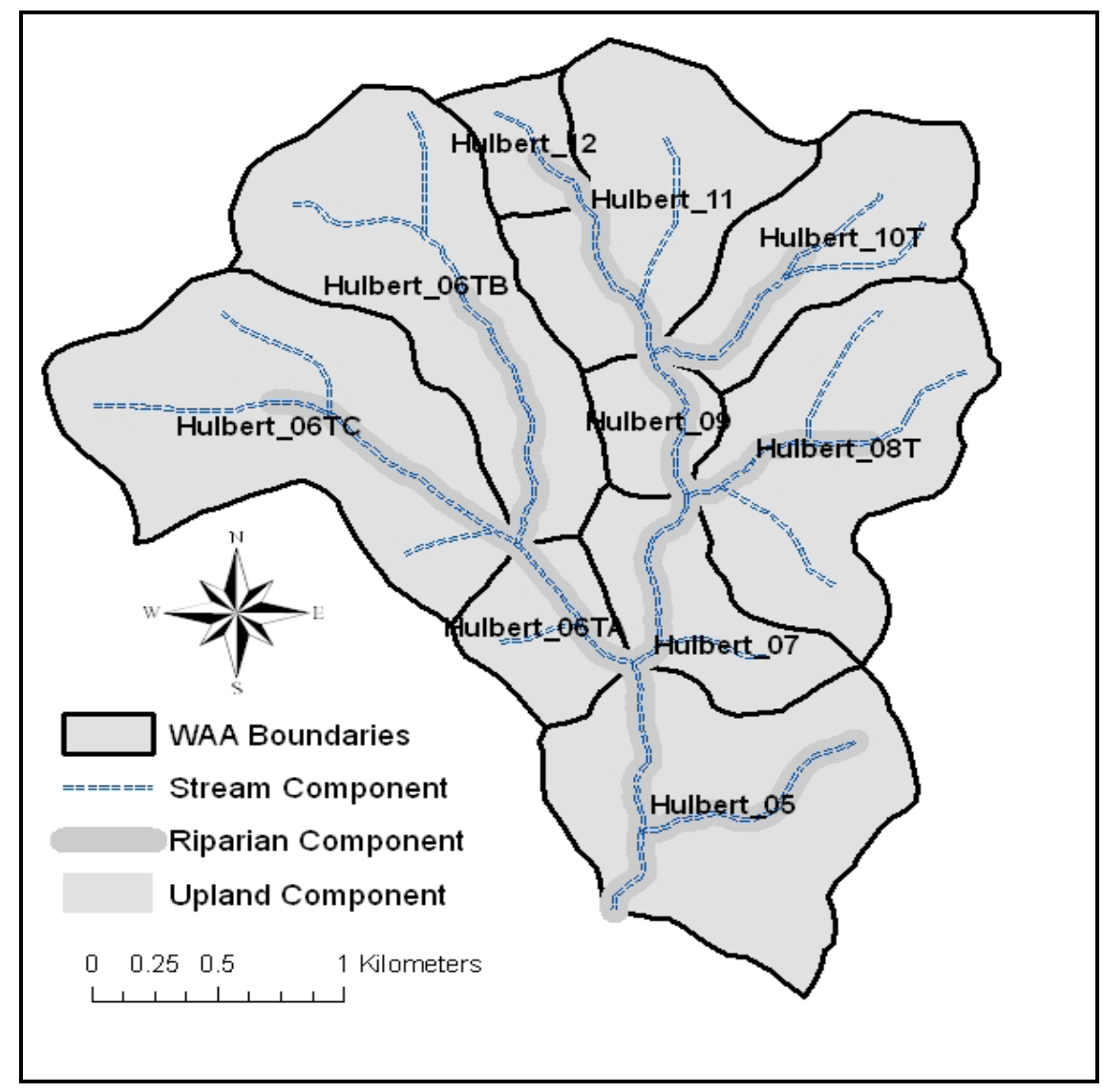

Figure 1. WAAs, local drainages, drainage basins, and stream, riparian, and upland components of the WAA. 
To facilitate multiple scale analysis, two types of drainage basin are defined for each WAA. The first type, the "local drainage basin," consists of the area that drains directly to the mainstem or tributaries in a WAA. The second type, the "drainage basin," consists of the local drainage basin of a WAA, in addition to the local drainage basins of all upstream WAA.

For example, in Figure 1, the local drainage basin for Hulbert_o9 includes just the area that drains directly to the mainstem and tributary channels in Hulbert_09. The drainage basin of Hulbert_09 includes the local drainage basin of Hulbert_09 in addition to the local drainage basins of Hulbert_07, Hulbert_10T, Hulbert_11, and Hulbert_12, since they are upstream of Hulbert_09. The local drainage basin and the drainage basin are the same for Hulbert_12 and Hulbert_o10T since there are no WAAs upstream.

\section{Defining ranking criteria and selecting indicators}

\section{Defining ranking criteria}

One of the significant challenges in implementing a watershed management plan is to effectively integrate the compiled data and information into the process that is used to make decisions concerning restoration, conservation, and economic development. To make these decisions, it is necessary to first define a set of ranking criteria on which these decisions can be based. These ranking criteria are what will be used to assess and rank individual watershed assessment units, and then in turn will serve as the basis for selecting among the many possible development, restoration, or conservation actions identified by the management plan. For example, if the inventory, assessment of condition, and restoration of anadromous fish stream habitat is an important management objective in the watershed, the ranking criteria and indicators related to this objective make it possible to identify areas in the watershed where anadromous fish stream habitat is of high quality, where restoration activities could potentially improve the quality of anadromous fish stream habitat, where conservation activities could potentially sustain existing, high quality anadromous fish stream habitat, or where development activities would have the least impact on anadromous fish stream habitat. 
MAWI evaluates four general primary ranking criteria:

1. Ecological condition

2. Vulnerability to future impact

3. Conservation potential

4. Restoration potential.

The ecological condition primary ranking criterion is defined as the degree to which current structural characteristics and physical, chemical, and biological processes in a WAA, or the drainage basin of a WAA, are within the range of natural variability, or satisfy some other measure of condition identified by regulation or published guidelines.

The vulnerability primary ranking criterion is defined as the degree to which the current, or predicted future, conditions in a WAA, or its drainage basin, have the potential to decrease in the future. For example, if a WAA has areas where future urban growth is projected to occur, the WAA is vulnerable to the myriad of potential impacts associated with development activities. Similarly, a WAA that includes areas with a high potential for slope instability is more vulnerable to road building and other activities with the potential to increase sediment erosion, and a WAA that supports anadromous fish would be considered vulnerable to activities with the potential to modify the stream channel such as in-channel mining, changes in flow, or the removal of riparian vegetation.

The conservation potential primary ranking criterion was defined as the degree to which baseline conditions in the WAA make it a candidate for conservation. For example, an upland, riparian, or stream component of a WAA might be identified as suitable for conservation based on its condition, the size of its habitat patches, the number of endangered or threatened species present, or the fact that it is publicly owned.

The restoration potential primary ranking criterion was defined as the degree to which current conditions in a WAA make it possible to increase the condition ranking criterion through restoration activities. For this criterion, the objective is to identify the areas where it would be possible to restore the greatest number of acres to a self-sustaining, natural condition for the least cost and effort (i.e., a "biggest bang for the buck" approach). For example, in uplands certain land use/land cover types have greater restoration potential because they can be restored with lower cost and 
effort than other land use/land cover types. There are lower costs and less effort associated with restoring an area of degraded native vegetation requiring small scale or spot planting and exotic plant control, than the cost and effort required to restore agriculture areas requiring minor earth work and large scale planting, or developed areas requiring infrastructure removal, major earth work, topsoil and seed bank replacement, and large scale planting.

Once the primary ranking criteria have been established, additional, secondary ranking criteria need to be identified. These criteria should be narrower in scope, and can be identified by reviewing any critical issues outlined in an existing management plan or other watershed and stream assessments. More specific criteria, for example, may be things like land use in upland areas, hydrologic regime for riparian areas, or habitat condition in streams.

\section{Selecting indicators}

To assess a criterion it is necessary to identify and then synthesize the factors that influence its condition. There are a variety of ways to synthesize information ranging from mechanistic models (e.g., hydrologic models such as Hydrologic Simulation Program Fortran and habitat models such as Instream Flow Incremental Methodology), to index-based methods (e.g., Index of Biological Integrity), to the use of best professional judgment. The selected approach depends on the objective and the time and resources available. However, in most cases, due to limited time and resources and/or the large spatial extent of the study area, the use of mechanistic models is not practical. Therefore, MAWI uses an indicatorbased approach to assess criteria condition.

Indicators are designed to quickly and easily communicate information about the condition of something of interest, and, over time, about changes or trends in the condition (National Research Council 2000). Ecological indicators are appropriate in cases where it is unnecessary, inefficient, or impossible to measure, model, or analyze at the highest level of detail to achieve the objectives of a study. For example, ecological indicators can be used to make informed decisions in a planning context, or in similar situations where relative comparisons are appropriate, spatial scales are large, and/or the time and resources required to conduct more detailed studies are unavailable. 
In the Baseline Watershed Assessment, indicators are defined as characteristics or processes that can be used to assess the condition of a WAA with respect to one or more ranking criteria. For example, water temperature, dissolved oxygen, pool frequency, pool depth, and canopy cover are all indicators that could be used to assess the condition of anadromous fish stream habitat. Indicators may be either direct or indirect. The distinction between direct and indirect indicators is somewhat arbitrary, but generally, direct indicators are those based on a well-documented, empirical relationship between an indicator and a ranking criterion, and indirect indicators are those based on weaker empirical relationships and/or expert opinion. Although the distinction is somewhat arbitrary, the direct/ indirect designation can be used to provide a relative indication of the strength of the empirical relationship between indicators and ranking criteria.

In general, several factors will influence the selection of indicators. The selected indicators must be applied over large areas, so low cost and rapid application are important factors. For this reason, indicators that can be evaluated remotely (i.e., through GIS processing of pre-existing spatial datasets) are preferred over indicators that require intense field data collection. It is also important that the relationship between the indicator and ecological function be clear, so that the model is transparent and understandable to all participating stakeholders, who would likely have a wide range of perspectives and interests. Finally, the selected indicators should be usable in a predictive mode, meaning that they should be capable of reflecting changes due to proposed impacts and restoration actions. Once these factors are considered, indicators can be selected based on a review of existing assessment methods, literature, field observations, available data, or the collective experience and expert judgment of individuals participating in the project.

\section{Develop a knowledge base using indicators and criteria}

The next step in the MAWI process is the development of a knowledge base. The addition of a knowledge base and its use of fuzzy logic is one of the most significant changes to MAWI since its original development. Previously, only simple logic models were used to combine and weight indicators in calculating integrity indices. Chapter 4 gives an example of a fully populated knowledge base. 
The MAWI approach has been updated to incorporate the use of fuzzy logic and knowledge bases for two main reasons. First, using fuzzy logic better reflects the uncertainty associated with the complexity of ecosystems and their processes than would purely mathematical models. Second, knowledge bases are able to handle missing data in the evaluation. Knowledge bases are able to assess the importance of these missing data to the evaluation, and report accordingly on the strength of the results. The following section gives some basic background on fuzzy logic and knowledge bases.

\section{Concepts of fuzzy logic and knowledge bases}

Fuzzy logic is a logic system that is able to incorporate the concept of "partial truth" (as opposed to classical Boolean logic, where things are either completely true or completely false). To use a simple example, using Boolean logic, a tree might be defined as "large" if it has a basal area (BA) of $\geq 1.0 \mathrm{~m}^{2}$. Therefore, a tree with a basal area of $1.2 \mathrm{~m}^{2}$ would be defined as large, while a tree of $0.8 \mathrm{~m}^{2}$ would not be defined as large. However, under fuzzy logic, a numerical "truth value" can be calculated for different BAs, based on a set of breakpoints. The breakpoints establish when something is either 100 percent true or 100 percent false. For the case of trees being large, one might create a rule that defines the 100 percent true breakpoint (a truth value of 1 ) as $\mathrm{BA} \geq 1.0 \mathrm{~m}^{2}$ (i.e., a tree of $\mathrm{BA}=1.1 \mathrm{~m}^{2}$ is definitely large), and the 100 percent false breakpoint (a truth value of -1) as $\mathrm{BA} \leq 0.2 \mathrm{~m}$ (i.e., a tree of $\mathrm{BA}=0.1 \mathrm{~m}^{2}$ is definitely not large). For any trees with a BA in between those two breakpoints, an intermediate truth value can be assigned so that a tree of $\mathrm{BA}=0.8 \mathrm{~m}^{2}$ might have a truth value of 0.75 , a tree of $\mathrm{BA}=0.4 \mathrm{~m}^{2}$ might have a truth value of -0.75 , and so forth. The relationship between BA and the truth value can then be depicted in a single "fuzzy curve" (Figure 2), which can be linear or otherwise in nature. To go a step further in this example, it is also possible that defining whether a tree is large is dependent on multiple criteria-for instance, the tree's height and crown area, in addition to basal area. Separate fuzzy logic-based relationships and truth values, similar to what was used for basal area, could be established for each additional criterion. 


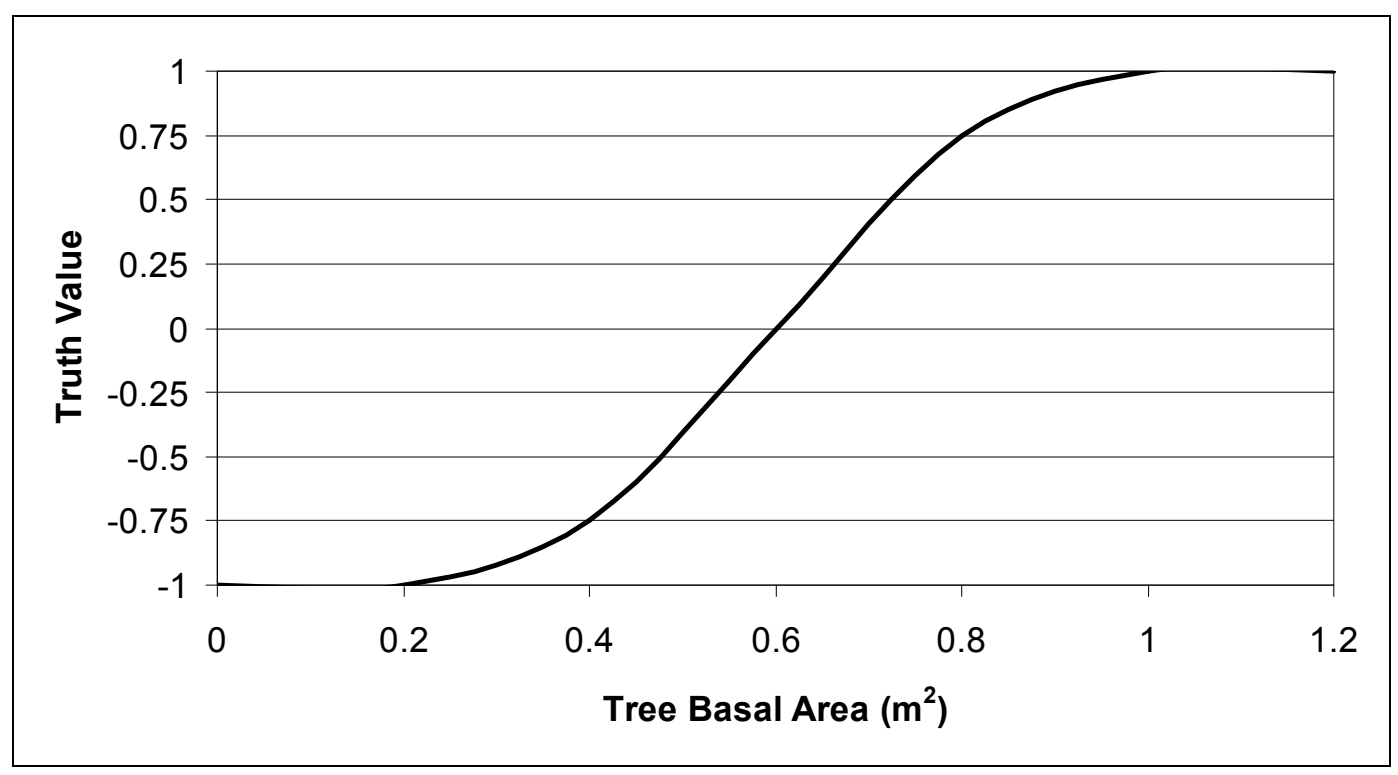

Figure 2. Fuzzy curve showing the relationship between tree basal area and truth value. In this example, the truth value is addressing the proposition as to whether or not a tree is "large." The truth values indicate the varying degree to which the proposition is likely to be completely true (truth value $=1$ ) or completely false (truth value $=-1$ ).

A knowledge base is simply a collection and combination of these rules and the ways in which they interact with each other (using logic operators such as AND, OR, NOT, etc.). In MAWI, the knowledge base contains the relationships between the indicators and the ranking criteria. These relationships can be determined based on literature, empirical evidence, and expert opinion. Ultimately, the knowledge base is used to answer the question, "given a set of criteria, to what extent does the data support a particular proposition?”

MAWI uses NetWeaver software to construct knowledge bases. The following section describes the structure and construction of a NetWeaver knowledge base.

\section{Incorporating NetWeaver into the MAWI approach}

NetWeaver is a knowledge base development system for the Microsoft Windows platform. It is licensed software published by Rules of Thumb, Inc. NetWeaver is designed to build knowledge bases in a top down and an incremental or modular fashion. The structuring of a MAWI knowledge base can be viewed as a hierarchical series of criteria linked together in a network. For example, an upland condition knowledge base at its top level would have a primary criterion and associated truth value that addresses the proposition that the upland portion of an assessment area is of high 
integrity (in that it meets a defined set of reference conditions). These reference conditions are defined by a series of secondary criteria. Each of these secondary criteria will have its own truth value that addresses how much it supports the primary criteria/proposition that the upland is of high integrity. Secondary criteria truth values are determined by one or more indicators, which are the actual data inputs into the model, and which, in turn, are also scaled into a truth value based on a set of breakpoints. Note that the knowledge base itself does not contain the actual data, but instead processes data that have been entered into it separately.

The NetWeaver knowledge base is described as modular because any indicator or criterion in it can be independently evaluated, and any number of criteria can be combined to create a higher level criterion. Therefore, the entire knowledge base does not necessarily need to be used if only specific indicators or criteria need to be evaluated.

\section{Structure of a NetWeaver knowledge base}

This section illustrates some of the general structure and relationships within a NetWeaver knowledge base, using a simplified example of a knowledge base for measuring upland condition. At the top of the knowledge base is the primary criterion that will be used to evaluate upland condition (Figure 3).

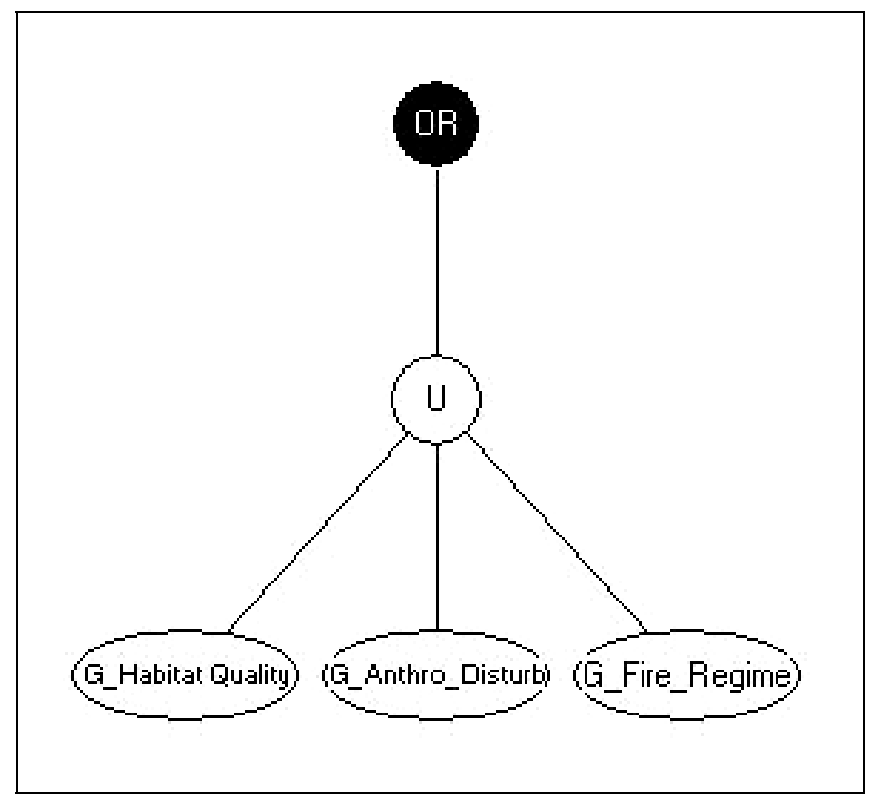

Figure 3. A primary criterion set up in NetWeaver. 
The "Upland Condition" primary criterion consists of three secondary criteria, which are habitat quality, human disturbance, and fire regime. These three criteria are joined together using the Union function, which is one of several functions available in NetWeaver to describe the interactions between variables. The Union function calculates the average truth value of the variables it links, so in this case the truth value of the Upland Condition criterion would be the average of the truth values of the habitat quality, human disturbance, and fire regime criteria. Criteria may consist of additional sub-criteria (depicted as ovals), or one or more data inputs (depicted as squares). The fire regime criterion, for instance, contains only one data input (Figure 4), while the human disturbance criterion (Figure 5) contains several data inputs, joined together by the UNION operator (this and other operators are explained further in the following "Determining Truth Values" section). The habitat quality criterion includes several additional criteria (Figure 6).

Going further down the network, the vegetation condition criterion (part of the habitat quality criterion) also contains two more criteria (Figure 7), one of which is "vegetation composition" (the "G_VC_veg_comp" oval). The vegetation composition criterion in turn contains two more criteria (Figure 7), however, these criteria are run through a "Switch Node" meaning only one of them is used in the analysis, based on data availability or quality. Therefore, the switch node is useful in situations where the same data type may not be available for all WAAs. The criteria are listed in order of preference of use, so in this case, the "PNV" (percent potential natural vegetation) criterion is optimal.

\section{Determining truth values in the NetWeaver knowledge base}

A truth value is determined for each indicator/data input and criterion in the knowledge base. The truth value of each data input, as it relates to the criterion of which it is a component, is based on: (1) a proposition that defines the 100 percent or totally true and 100 percent or totally false conditions, and (2) a defined relationship between the truth value and the indicator's data input. The sub-components of each criterion can be differentially weighted to change their influence in determining the truth value of the higher ranking criterion. The sub-components can be aggregated through a variety of either normal arithmetic or logic operators. 


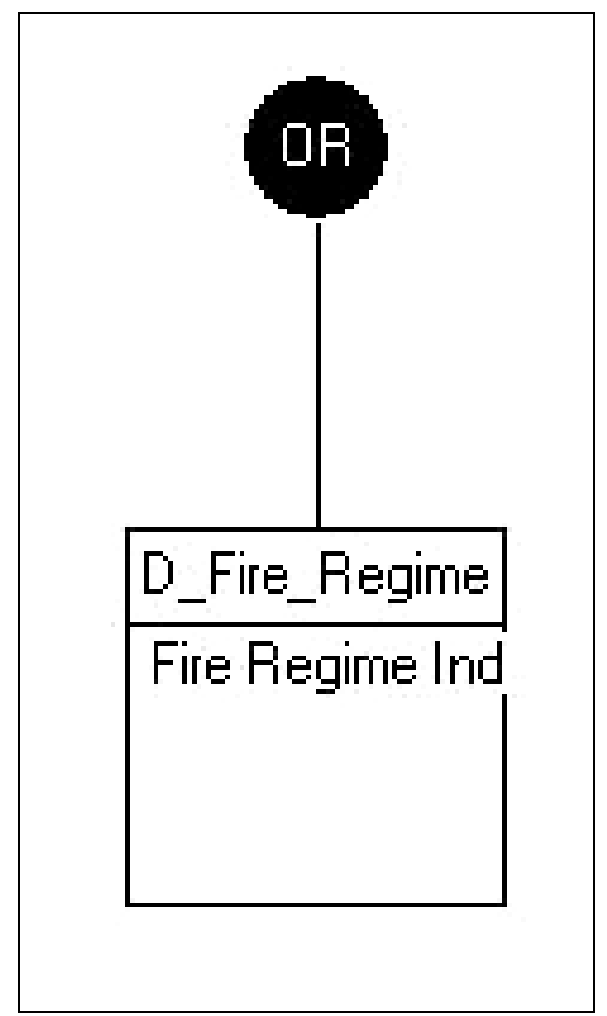

Figure 4. Fire Regime criterion set up in NetWeaver, containing only one data input.

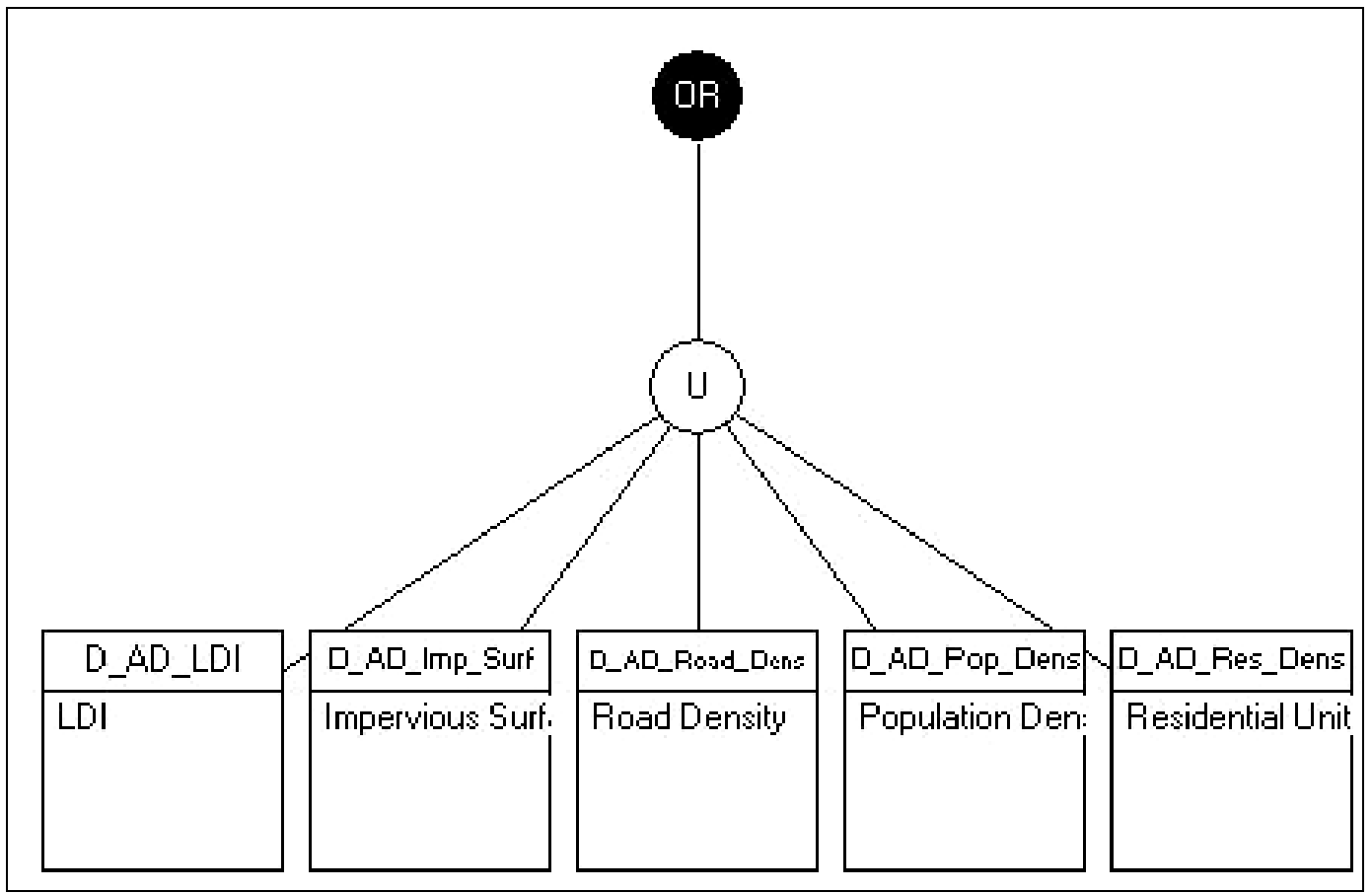

Figure 5. Human disturbance criterion set up in NetWeaver, containing multiple data inputs. 


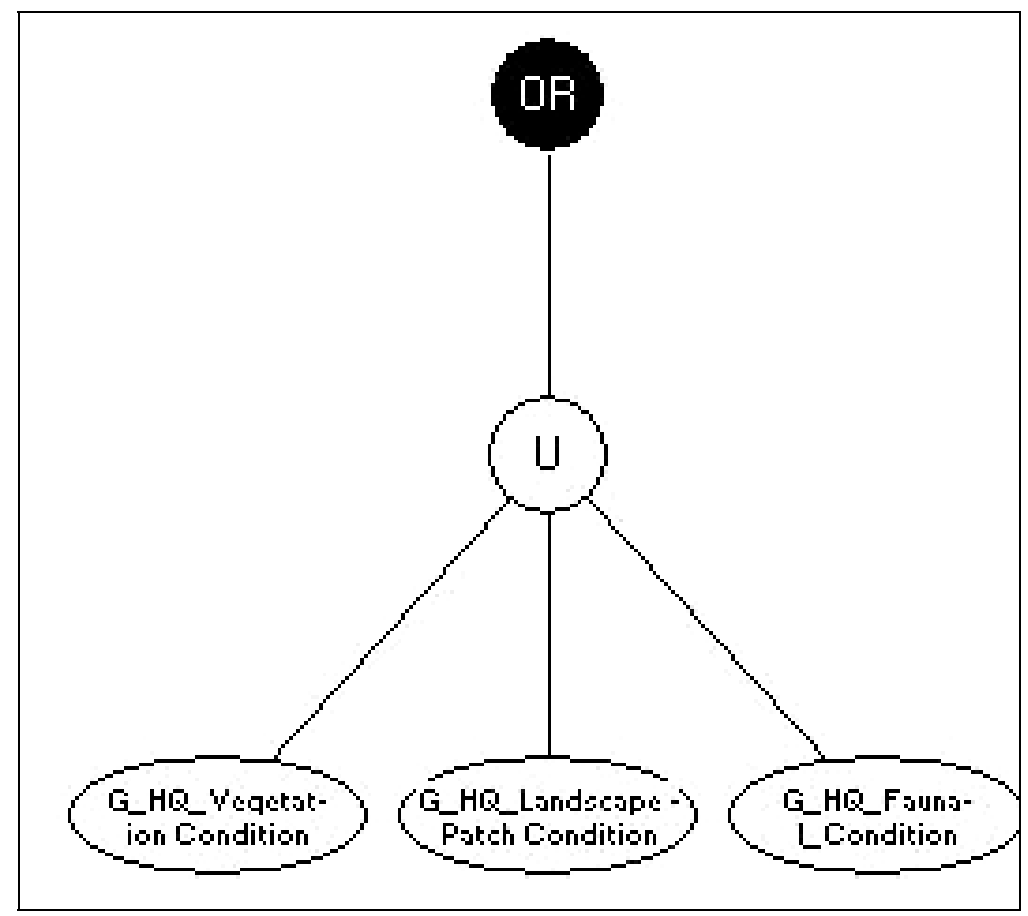

Figure 6. Habitat Quality criterion set up in NetWeaver, composed of multiple criteria.

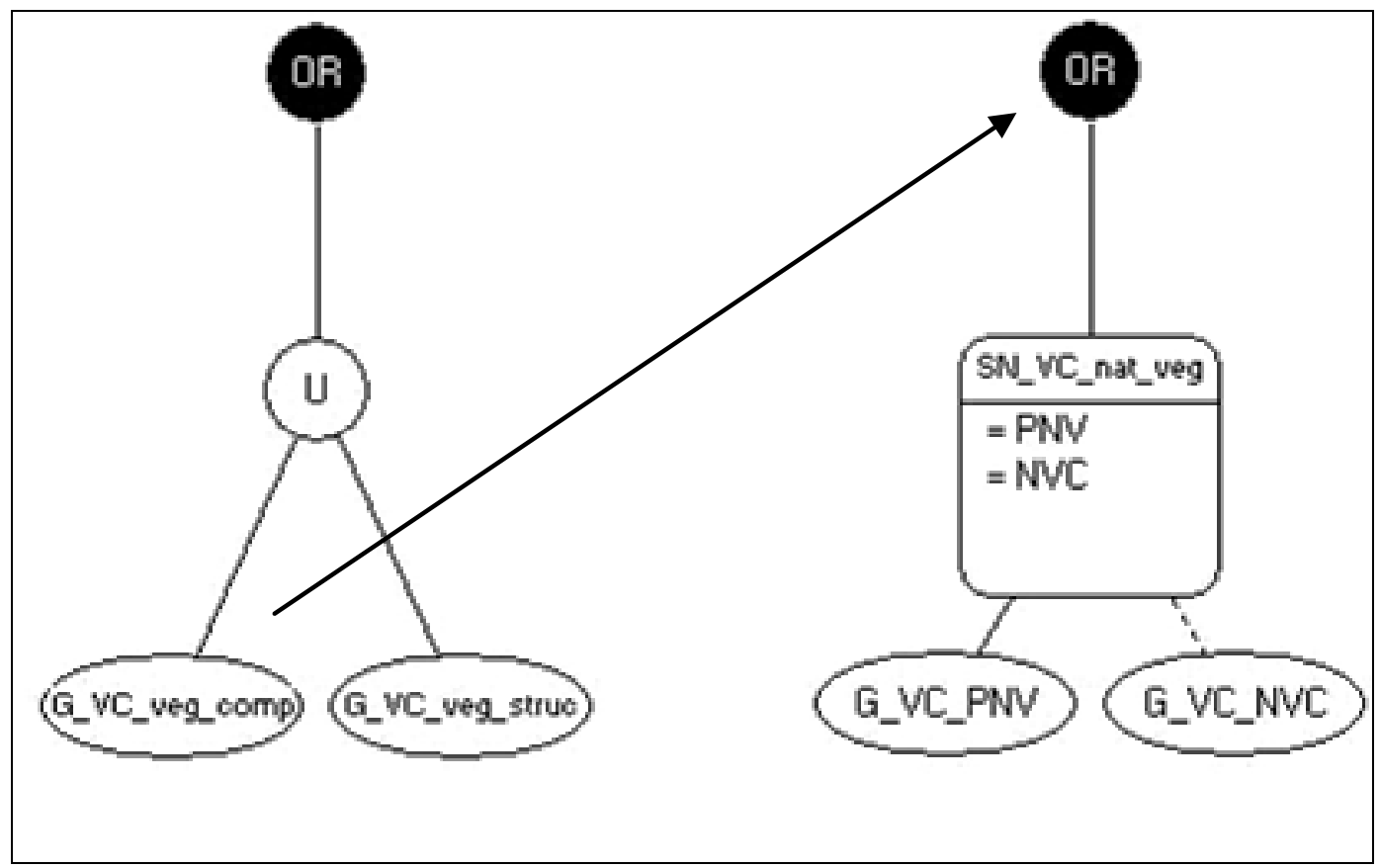

Figure 7. On the left is the Vegetation Condition criterion set up in NetWeaver, composed of two criteria. On the right is one of these criteria, vegetation composition, which operates on a "Switch Node." 
For example, UNION is a normal operator that calculates the truth value of a criterion by taking the weighted average of the truth values of its subcomponents. On the other hand, OR is a logic operator where the truth value of the criterion it is operating on is the maximum truth value of its sub-components. Other operators that can be used in NetWeaver are "AND," "IF," "NOT," "Sequential OR," and "Exclusive OR."

The relationship between the indicator metric and truth value may be based on field data, literature values, expert opinion, intuitive reasoning, or derived empirically from WAA metric values. The Fire Regime Condition Class Indicator is shown here as one example of how truth values can be developed using field data and literature values, in this case using an existing condition index. The indicator is based on the proposition that upland portions of a WAA have a fire regime that is within the range of natural variability based on the values of a set of factors, including vegetation characteristics, fuel composition, fire frequency, severity, and pattern; and other associated disturbances (i.e., insect and disease mortality, grazing, and drought).

The data input for the Fire Regime Condition Class Indicator consists of a Fire Regime index that ranges from Class 1 to Class 4, where: Class 1 indicates that an area does not significantly deviate from the range of natural variability for the factors comprising the index; Class 2 indicates a moderate deviation from the natural range of variability for one or more of these factors; Class 3 indicates a significant deviation from the natural range of variability for one or more of these factors; and Class 4 indicates that a natural fire regime no longer exists. The relationship between the value of Fire Regime Condition Indicator data input and the truth value, as stated in the proposition above, is defined in the graph shown in Figure 8. When the Fire Regime Condition Index is Class 1, a truth value of 1 is assigned because the fire regime condition is fully consistent with the proposition (i.e., does not significantly deviate from the range of natural variability). As the Fire Regime Condition Index increases, the truth value decreases indicating greater deviation from the proposition, until a truth value of -1 is assigned when the Fire Regime Condition Index is Class 4. 


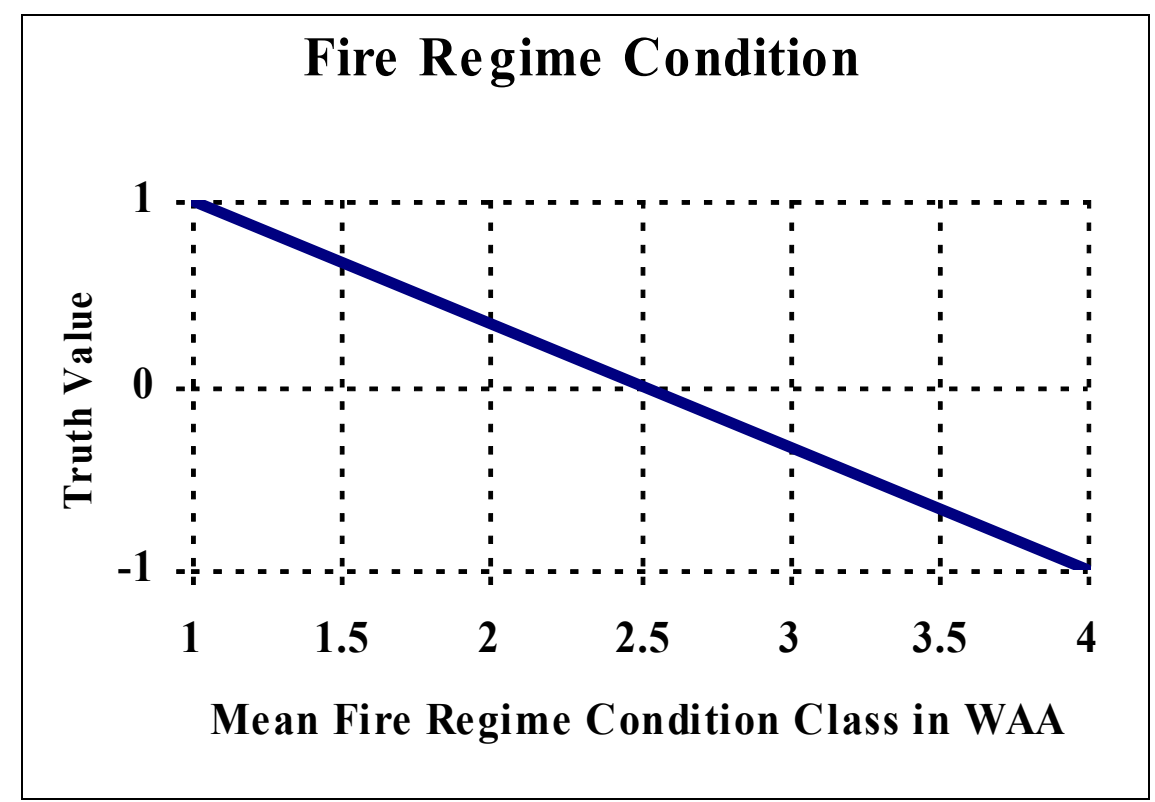

Figure 8. Literature-derived relationship between truth value Fire Regime Condition Class Indicator.

An example of an intuitively derived relationship is the Native Vegetation Communities indicator shown in Figure 9. The indicator is based on the proposition that upland portions of a WAA support native vegetation communities. The data input for this indicator is the percent of a WAA with a native vegetation community land cover. It is intuitive that, under natural conditions, native vegetation communities should cover 100 percent of a WAA and thus be assigned a "totally true" truth value of " 1 ," and that when native vegetation communities cover none of the WAA, a "totally false" value of “-1" is assigned (Figure 9).

For some indicators, there is no field data, literature values, expert opinion, or intuitive basis for defining the relationship between the indicator metric and truth values. In these situations, an empirical approach should be used. Specifically, the mean and standard deviation for all WAA data inputs for that indicator are calculated, and a linear approximation of the normalized cumulative distribution function is used, with the $10^{\text {th }}$ and $90^{\text {th }}$ percentiles serving as the totally false (“-1") and totally true (" 1 ") truth values. An example of this type of relationship is the population density indicator, shown in Figure 10. While the results are not comparable outside of the particular watershed being studied, this approach for establishing truth value still provides a relative comparison of WAAs in terms of the particular indicator. 


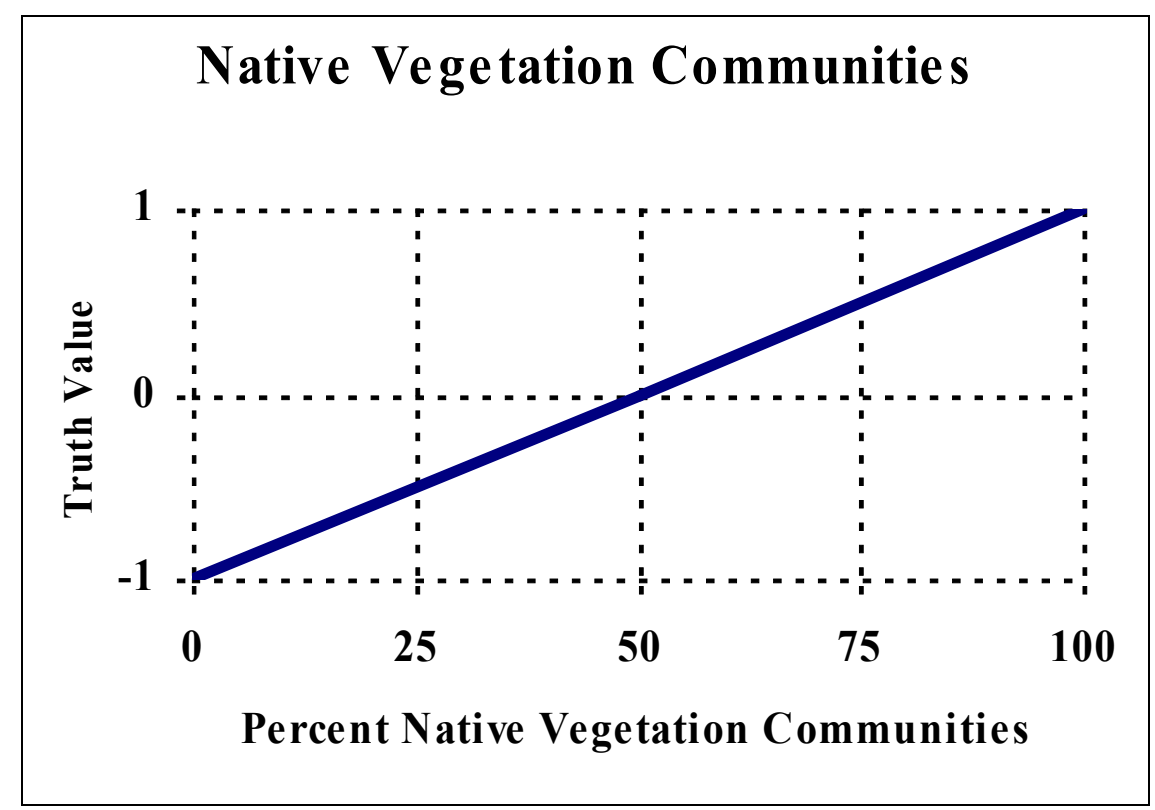

Figure 9. Intuitively derived relationship between truth value and Native Vegetation Communities indicator.

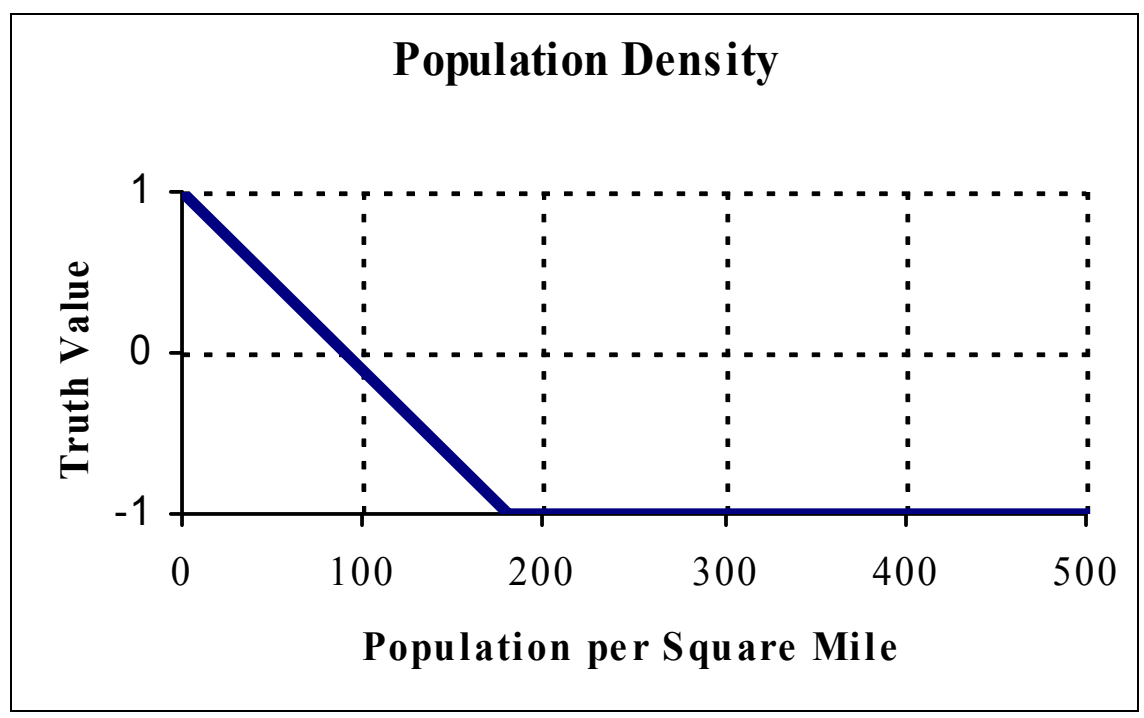

Figure 10. Empirically derived relationship between truth value and data input for Population Density indicator.

\section{Use the knowledge base to assess WAAs in terms of criteria}

The final step is to apply the knowledge base to the data that have been accumulated in the first step of the MAWI process to assess the individual WAAs. The platform used in MAWI for applying the knowledge base and generating and displaying results (criteria and indicator truth values for each WAA) is the Ecosystem Management and Decision Support (EMDS) software (Reynolds 2003). 
The EMDS system, which is public domain software created and distributed by the USDA Forest Service, is the interface currently used by MAWI to translate the results of the NetWeaver-created knowledge bases into graphical displays using ESRI ArcGIS. EMDS also easily allows for alternative or "what-if" scenarios to be run. These scenarios can be created by changing the indicators or the interactions among indicators within the knowledge base, changing breakpoints, or changing actual data values. This feature can be used to test the knowledge base (seeing what happens if certain criteria or indicators are ignored, for instance), or explore the implications of multiple alternative future conditions.

Once a NetWeaver knowledge base has been created, a database file (.dbf) can be generated and populated with the data necessary to evaluate the truth values of the various indicators and criteria. The dbf is then linked to an ArcGIS shapefile containing the WAAs to be analyzed. This shapefile, along with the associated knowledge base, can then be processed by EMDS, which will generate various map and tabular outputs. Maps showing categorized truth values can be generated for any criterion or indicator. EMDS categorizes truth values into "levels of support." For a criterion or indicator to be "fully supported" it needs a truth value of 1.o.

Figure 11 shows an example of a map output generated in EMDS. The map depicts the categorized truth values for the upland condition criterion in individual WAAs in the Russian River watershed. The results are also output in a table of the actual truth values for all criteria (Figure 12).

\section{Summary}

The MAWI approach can be applied in five general steps, although these steps do not necessarily need to be sequential and can be iterative. Once the principal objectives and focus of a watershed assessment have been established, pertinent available data are assembled, assessment models are structured, and a knowledge base is developed that relates indicator values to overall indices of condition. The models are applied within subunits of the watershed, termed Watershed Assessment Areas, which can be aggregated to allow assessments to be conducted at various scales. 


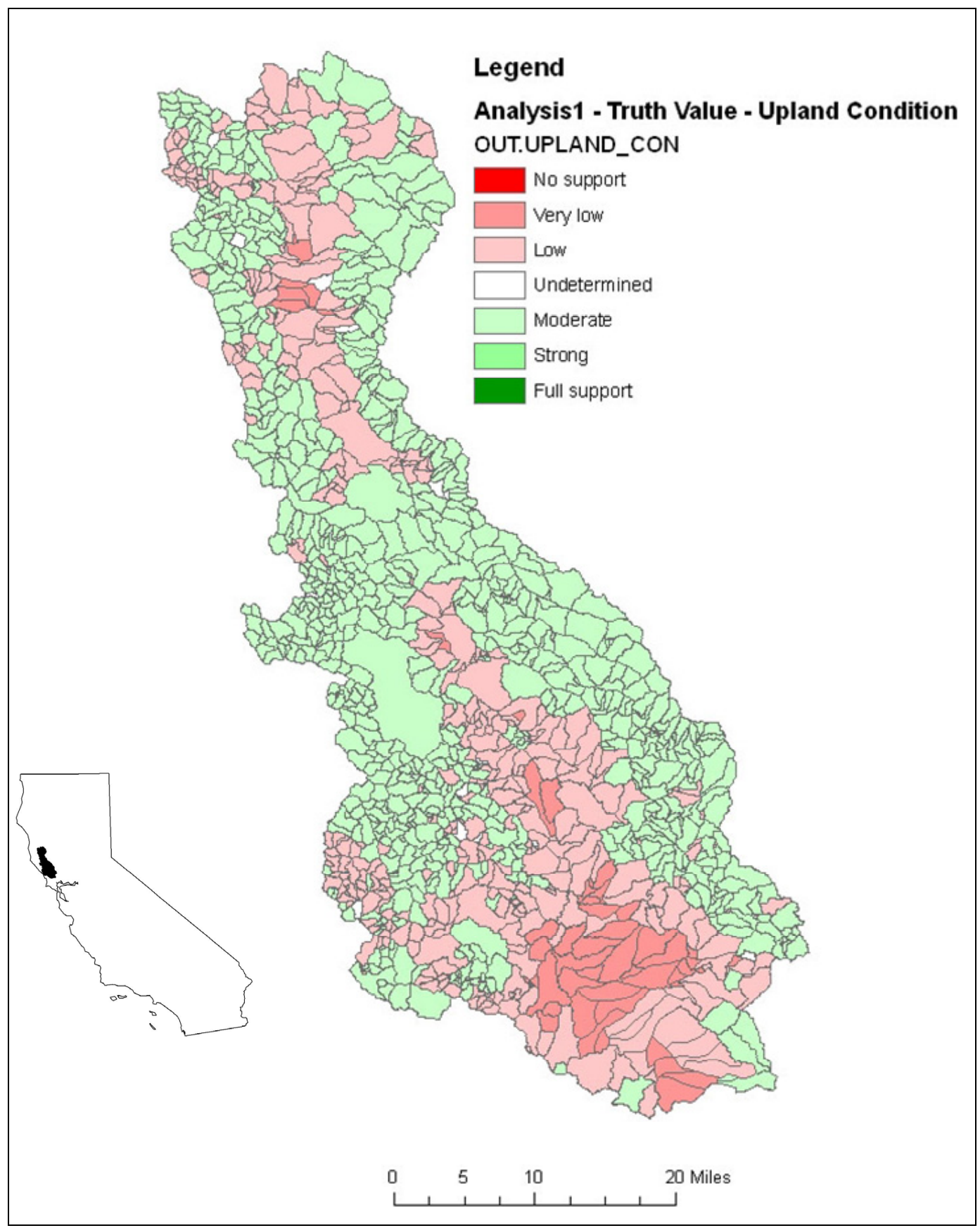

Figure 11. An EMDS map output, showing categorized truth values for an Upland Condition criterion in individual WAAs in the Russian River Watershed, located in northern California. Truth values were generated using the example Upland Condition knowledge base presented in the "Structure of a NetWeaver Knowledge Base" section of this report (Figures 3-7), and then categorized within EMDS. The categories reflect a "level of support" for the proposition that the upland portion of the WAA is in a relatively natural or unaltered condition. In other words, based on the available data, the uplands in the green-colored WAAs are more likely to be in good condition than those in the red-colored WAAs. In this example, data were not available for any of the indicators in the landscape patch condition or faunal condition criteria. Because of this missing data, it is impossible for any WAAs to have "full support" for the Upland Condition criterion. 


\begin{tabular}{|c|c|c|c|c|c|c|c|c|}
\hline & & & & & & & & 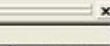 \\
\hline & FEATURE ID & UPL COND & G ANTHRO D & $\mid D A D$ LDI & D AD IMP S & DD AD ROAD & D AD POP D & D AD RE * \\
\hline 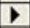 & 1 & G_VC_veg_struc & .0 .237 & 4.1 & 4.4 & 3.3 & 146.1 & 56.6 \\
\hline & 2 & & -0.653 & 6.1 & 25.7 & 12.8 & 3666.4 & 1023.4 \\
\hline & 3 & G_VC_veg_struc & -0.311 & 4 & 1.5 & 3.4 & 139.1 & 75.6 \\
\hline & 4 & G_VC_veg_struc & 0.151 & 3.5 & 0.3 & 3.4 & 20.5 & 10.4 \\
\hline & 5 & & -0.63 & 6.2 & 30.6 & 13.6 & 5217.8 & 1203 \\
\hline & 6 & G_VC_veg_struc & 0.036 & 2.4 & 0.4 & 2.2 & 45.3 & 26.4 \\
\hline & 7 & & 0.591 & 4.7 & 4.8 & 6.2 & 314.5 & 201.8 \\
\hline & 8 & G_VC_veg_struc & 0.496 & 2.7 & 0.2 & 2.2 & 184.1 & 95.5 \\
\hline & 9 & G_VC_veg_struc & 0.549 & 3.7 & 3 & 3.4 & 494.5 & 151.7 \\
\hline & 10 & & -0.583 & 6.3 & 38.9 & 12.2 & 2181.3 & 727.8 \\
\hline & 11 & & 0.469 & 4.7 & 3.5 & 4.6 & 184.8 & 92.1 \\
\hline & 12 & G_VC_veg_struc & -0.647 & 5 & 3.1 & 8.1 & 617.2 & 310.1 \\
\hline & 13 & $G_{-} V C_{-} N V C$ & 0.822 & 1.8 & 0.2 & 9.2 & 345.7 & 356.6 \\
\hline & 14 & G_VC_veg_struc & 0.597 & 3.7 & 1.3 & 4.7 & 335.8 & 184.9 \\
\hline & 15 & G_VC_veg_struc & -0.62 & 4.2 & 8.1 & 6.9 & 1532.2 & 445.1 \\
\hline & 16 & & 0.609 & 5.5 & 9.9 & 8.4 & 343.7 & 204.7 \\
\hline & 17 & & -0.644 & 3 & 0.5 & 5.2 & 344.2 & 387.3 \\
\hline & 18 & & .0 .588 & 4.3 & 10.4 & 6.3 & 1566.1 & 459.5 \\
\hline & 19 & & 0.629 & 5.7 & 7 & 8.9 & 887.6 & 442.5 \\
\hline & 20 & G_VC_veg_struc & -0.252 & 2.9 & 0.3 & 3.6 & 119.4 & 55.8 \\
\hline & 21 & G_VC_veg_struc & .0 .67 & 2.6 & 0.4 & 5.5 & 329.6 & 267.4 \\
\hline & 22 & G_VC_veg_struc & -0.297 & 2.8 & 0.6 & 3.3 & 133.1 & 61.9 \\
\hline & 23 & & -0.656 & 4.4 & 1.1 & 7.4 & 421.8 & 367.1 \\
\hline & 24 & & 0.596 & 4.7 & 3.6 & 6.2 & 567.3 & 285.2 \\
\hline & 25 & & -0.569 & 4.9 & 7.6 & 6.1 & 421.9 & 158.6 \\
\hline & 26 & & 0.551 & 4.4 & 15.5 & 5.9 & 1048.7 & 318.2 \\
\hline & 27 & & -0.625 & 4.2 & 2.9 & 6.4 & 665.3 & 355.4 \\
\hline & 28 & G_VC_veg_struc & 0.767 & 2.8 & 2 & 10.5 & 166.8 & 120.2 \\
\hline & 29 & & 0.626 & 4.4 & 0.8 & 6.4 & 437.9 & 323.1 \\
\hline & 30 & G_VC_veg_struc & -0.19 & 2.5 & 0.3 & 2 & 114.9 & 50.9 \\
\hline & 31 & G_VC_veg_struc & 0.898 & 1.7 & 0.4 & 11.5 & 288.6 & 202 \\
\hline & 32 & G_VC_NVC & -0.604 & 2.4 & 0.6 & 5.4 & 185.8 & 93.1 \\
\hline & 33 & $G_{-} V C_{-} N M C$ & 0.719 & 1.5 & 0.1 & 8.5 & 179.1 & 90.8 \\
\hline & 34 & G_VC_veq_struc & 0.928 & 1.8 & 0 & 18.4 & 378.6 & 312.4 \\
\hline & 35 & G_VC_veg_struc & -0.924 & 1.9 & 0.1 & 19.7 & 379.2 & 301.3 \\
\hline & 36 & G_VC_veg_struc & 0.946 & 1.3 & 0.4 & 32.3 & 1003.7 & 561.1 \\
\hline & 37 & & -0.554 & 5 & 16.7 & 6.9 & 1556.6 & 464.3 \\
\hline & 38 & G_VC_veg_struc & 0.934 & 1.6 & 0.5 & 20 & 977.9 & 471.3 \\
\hline & 39 & G_VC_veg_struc & .0 .764 & 2.3 & 0.1 & 8 & 227 & 133.4 \\
\hline & 40 & $G_{-} V C_{-} N$ NC & -0.796 & 1.4 & 0.4 & 10 & 182.8 & 96 \\
\hline & 41 & G_VC_veg_struc & 0.677 & 2 & 0 & 4.9 & 298.1 & 116.4 \\
\hline & 42 & G_VC_veg_struc & -0.576 & 2.2 & 0.1 & 13.1 & 143.9 & 44.5 \\
\hline & 43 & & 0.444 & 3.1 & 0.7 & 8 & 157.4 & 50.4 \\
\hline & 44 & & -0.614 & 5.4 & 13 & 8.8 & 1704.3 & 724.3 \\
\hline
\end{tabular}

Figure 12. An example of tabular output created in EMDS, which shows the truth values for all indicators and criteria.

A major improvement to the MAWI approach has been the incorporation of EMDS/NetWeaver software. That change conveys a number of advantages over the original approach:

- Model variables and interactions are explicit and transparent.

- Models are easily modified, and their modular nature makes them easy to transfer and adapt for almost any study area.

- It is easy to run alternative scenarios.

- The importance of missing data can be incorporated into the analysis.

- Results are easily linked to GIS map outputs. 


\section{Potential Applications of the MAWI Approach}

\section{Using MAWI to assess impacts from project alternatives}

Once the knowledge base has been constructed and the baseline watershed assessment is completed, MAWI can then be used to evaluate the impacts to various aspects of watershed condition resulting from proposed development or management activities that would affect land use or water flow within the watershed.

Impacts are evaluated by projecting changes in indicator data values and their effect on the primary condition criterion, and then comparing the results to the baseline assessment. Because the indicators used in the MAWI analysis are individually evaluated (i.e., a truth value is determined for each one), transparent, and spatially explicit, MAWI can be used to identify the particular aspects of a project that might have the most (or least) impact on ecosystem conditions in a specific WAA. Therefore, if possible, adjustments to the project can be made to eliminate or minimize these impacts.

Because some of the indicators used for riparian and stream-related criteria are measured within an individual WAA while others are evaluated throughout its entire drainage basin, MAWI can identify indirect impacts to WAAs as well as direct impact from project footprints. The ability to identify indirect impacts to WAAs is important because it allows planners to recognize potential threats to critical resources, such as endangered species, even when their habitat will not be directly impacted by project activities. Figure 13 can be used to compare the areas affected by both direct and indirect impacts from two hypothetical project alternatives in a selected portion of the Russian River watershed. Figure 14 shows how the magnitude of these impacts can be expressed in terms of a decrease in truth value for a condition criterion, where the greater the decrease, the greater the impact. 


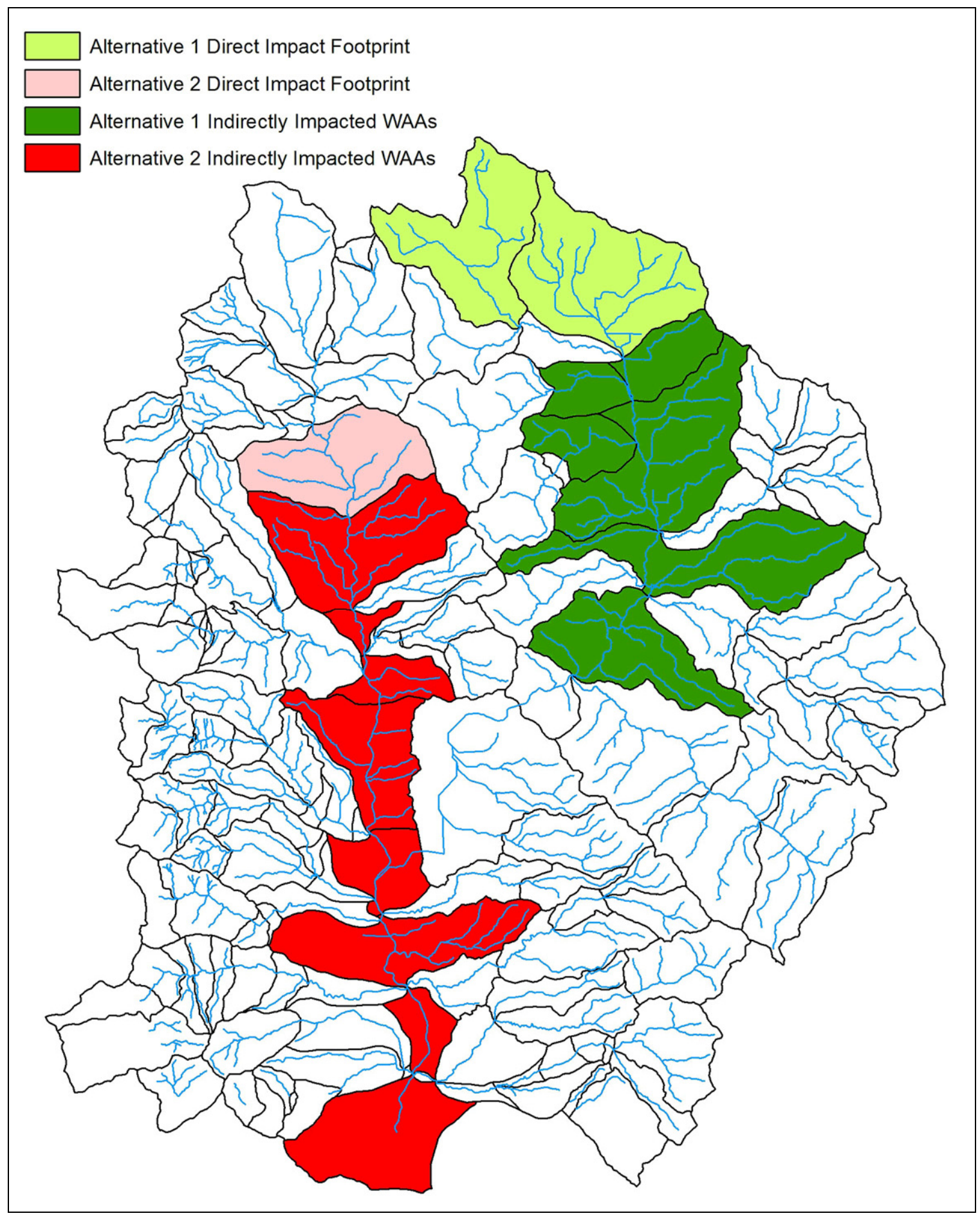

Figure 13. Comparison of WAAs directly and indirectly impacted by two hypothetical project alternatives in a selected portion of the Russian River watershed. 


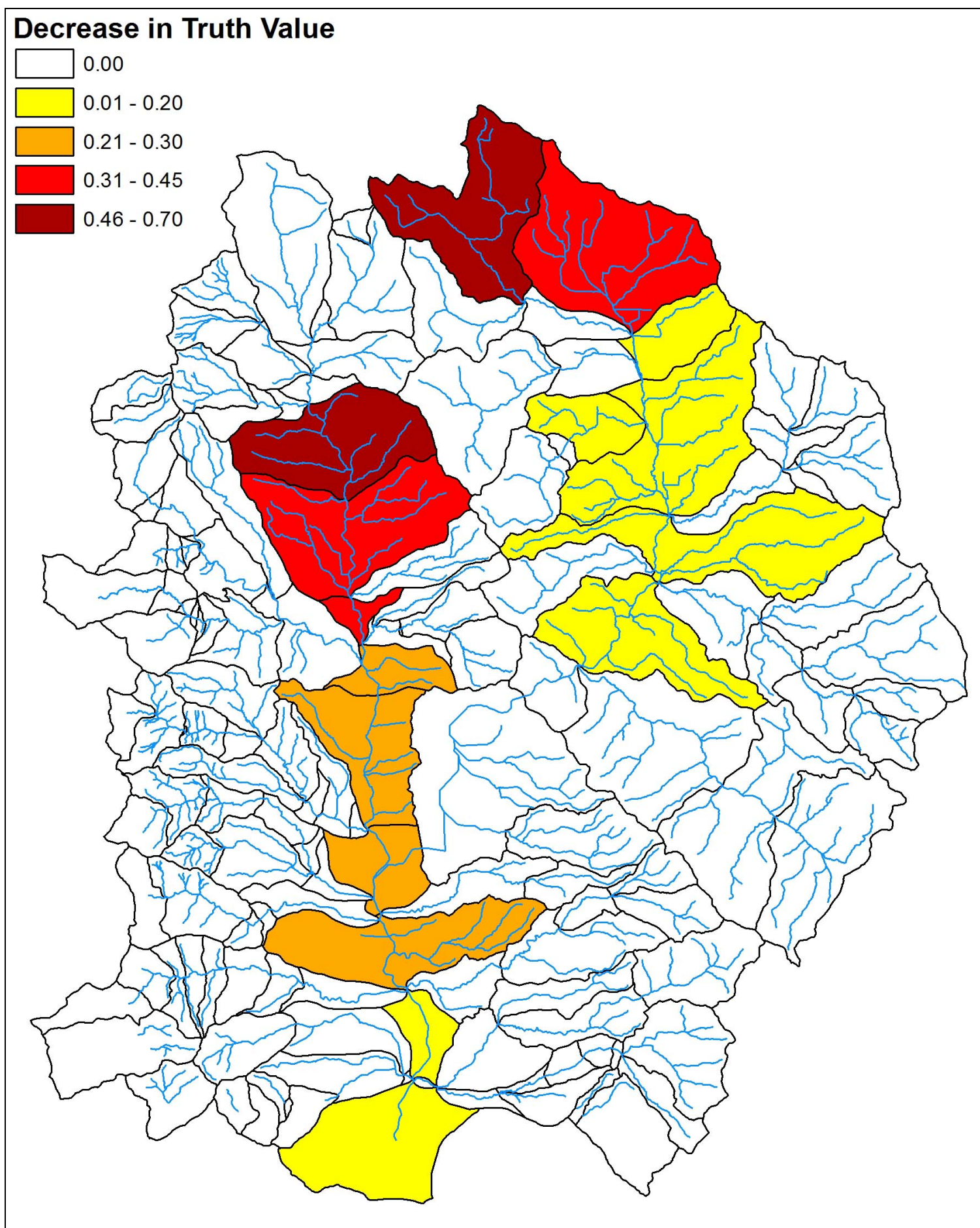

Figure 14. Decreases in truth value to a condition criterion in individual WAAs as a result of impacts from two hypothetical project alternatives in a selected portion of the Russian River watershed. 


\section{Using MAWI to prioritize restoration and conservation options}

The MAWI baseline watershed assessment can be used to evaluate project impacts, and also to determine where best to focus restoration efforts in the watershed, through the use of the restoration potential criterion. Using this criterion, WAAs are evaluated based on the level of cost/effort required to restore it to a self-sustaining and natural condition. Using this standard, both WAAs containing primarily areas of native vegetation, and WAAs with highly developed, urbanized areas would have low truth values for the restoration potential criterion. In the first case, very little acreage would need to be restored because the WAA is already in a natural condition, and in the latter case, the cost of restoration would likely be prohibitive. The vulnerability and conservation potential primary criteria can also be used in a similar fashion, to target areas that would benefit from protective management measures. Figure 15 shows an example of map output depicting categorized restoration potential truth values.

\section{Developing a nationwide MAWI knowledge base}

To date, the updated MAWI approach has only been applied to a single, large, watershed (the Russian River) in northern California, using a knowledge base that was created specifically for that system. However, because of the modular and comprehensive nature of the NetWeaver knowledge base used in this study, the Russian River MAWI knowledge base has the potential to be adapted and applied to any watershed in the country. Furthermore, all criteria and indicators used in the Russian River knowledge base are well documented as to their rationale for inclusion and include associated references, thus making the knowledge base transparent, understandable, and defensible.

The Russian River MAWI knowledge base contains three separate components: one for upland areas, one for riparian areas, and one for streams/ rivers, and all three contain primary criteria of ecological condition, vulnerability to future impact, conservation potential, and restoration potential. Each of these components and their corresponding primary criteria are stand-alone knowledge bases, meaning they can each be evaluated individually, or not at all. As an example, the Russian River knowledge base for Upland Condition is provided in following chapter. 


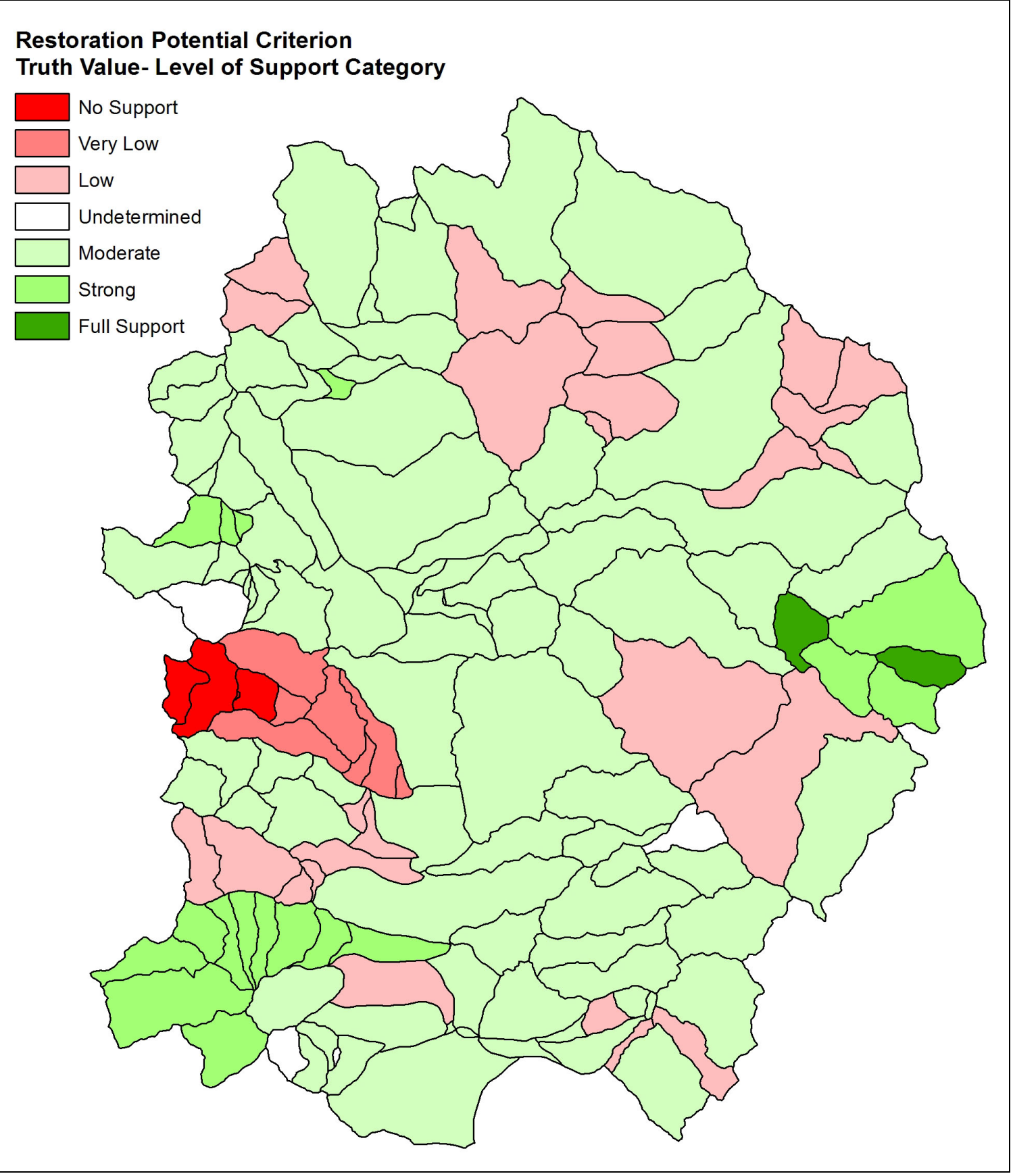

Figure 15. Hypothetical categorized truth values of individual WAAs for a restoration potential criterion in a selected portion of the Russian River watershed. The WAAs in green (moderate, strong, and full support) are good target areas for restoration, meaning that a large number of acres can be restored to a natural condition for minimal cost.

Most of the secondary criteria and indicators used are general enough to be applied in other watersheds across the country, and in cases where they are not, the knowledge base can be easily modified by removing or adding new criteria and indicators, manipulating interactions between model elements, or changing data input breakpoints, based on resource 
priorities, data availability, and specific needs and features in the watershed. It may also be the case that indicators used in the Russian River MAWI knowledge base are relevant in another watershed being analyzed, but the specific data inputs used by the indicator are not available. If this is the case, there are a few options for addressing this issue:

1. The indicator can be left out of the analysis.

2. The indicator can be treated as having missing data, and thus assigned a truth value of "o."

3. An alternative data input can be used for the indicator.

Any of these changes can be made based on professional judgment, literature, empirical evidence, and/or previous models. 


\section{An Upland Condition Knowledge Base Example}

\section{An Upland Condition knowledge base}

This chapter contains the details and various components of an upland condition knowledge base that was created for the Russian River Watershed in Northern California. Figure 16 shows a schematic of the Upland Condition knowledge base. This appendix can be used as a general example of how to document, structure, and populate another knowledge base, or as a starting template for using the MAWI approach to assess upland condition in other watersheds. An overview of all criteria and indicators used in the knowledge base is given. For each indicator, information is provided on the proposition being addressed, the data input being used and method for measuring it, and the truth value scaling and breakpoints. However, note that, for several of the indicators, the truth value breakpoints are determined based on reference values calculated for the Russian River watershed and thus are probably not transferable outside of that area. Knowledge bases for Upland, Riparian, and Stream Vulnerability, Restoration Potential, Conservation Potential, and Riparian and Stream Condition have also been created for the Russian River Watershed although the details of those knowledge bases are not presented here. However, these knowledge bases can also be adapted for use in other watersheds.

\section{Upland Condition (primary criterion) - overview}

The Upland Condition primary criterion assesses the overall condition of uplands in each WAA. It is defined as the degree to which current structural characteristics and physical, chemical, and biological processes in the upland portions (or local drainage basin) of the WAA are within the range of natural variability, consistent with condition specified by regulation or published guidelines, or in the highest 10 percent of all WAA truth values. It is based on a union of the Fauna Condition, Vegetation Condition, and the Human Stressors secondary criteria. Each of these criteria is discussed in greater detail below. 


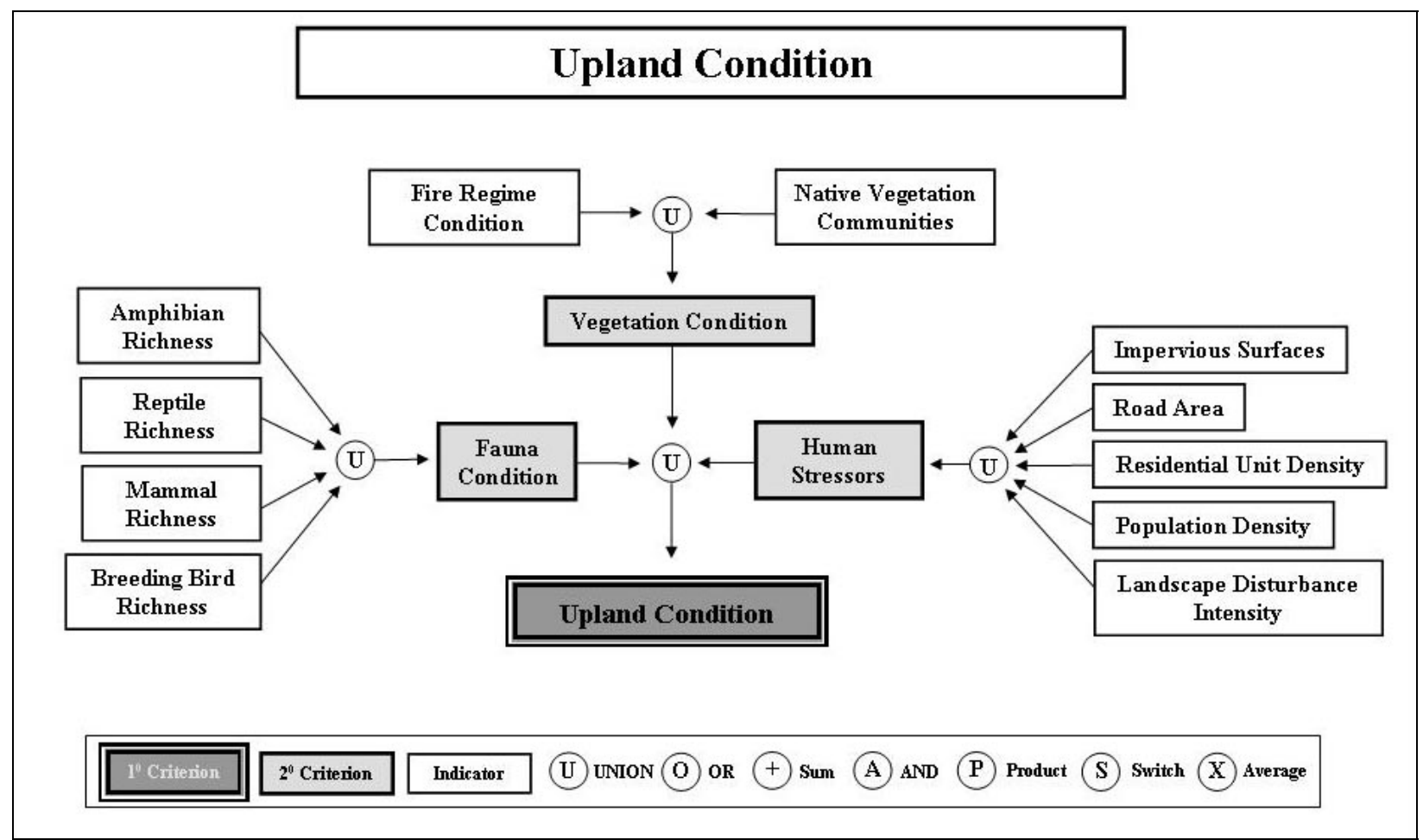

Figure 16. Overview schematic of the Upland Condition knowledge base.

\section{Vegetation Condition (secondary criterion) - overview}

The Vegetation Condition criterion is based on the presence, composition, and structural characteristics of native vegetation communities in the WAA. It is generally not possible to assess the species composition and structural characteristics of vegetation using field-based vegetation data because such datasets typically do not exist for an entire watershed. The alternative is to use remote imagery datasets, which may not have the level of detail and accuracy of a field survey, but which usually may be more readily obtained.

The two indicators used to assess vegetation condition are Native Vegetation Communities and Fire Regime Condition Class (FRCC). The FRCC indicator "overlaps" with the Native Vegetation Communities indicator in that it is based to some degree on the presence of native vegetation communities. Despite the apparent redundancy, in the Russian River both indicators are currently being used to assess the Vegetation Condition criterion for several reasons. First, the two indicators are based on different scales of resolution, with the Native Vegetation Communities indicator at a scale of $30 \mathrm{~m}$, and the FRCC indicator at a scale of $100 \mathrm{~m}$. Second, the FRCC indicator is based on native vegetation communities as well as other 
factors related to vegetation structure, fire, and disturbance. Third, the two indicators are developed independently and not highly correlated $(\mathrm{r}=-0.51)$ at the WAA spatial level. It is difficult to determine whether the moderate correlation reflects dataset errors, different scales of resolution, the additional vegetation structure factors used in the FFCC indicator, or "noise" introduced by the fire and disturbance factors used in the FRCC indicator. The FRCC indicator is the preferred indicator of vegetation condition, primarily because it includes factors related to vegetation structure, and is based on established reference conditions. However, until ground truthing can be done to ascertain why the two indicators are only moderately correlated, both indicators are being used to assess vegetation condition.

\section{Presence of Native Vegetation Communities (indicator) - overview}

\section{Overview}

The Native Vegetation Communities indicator assesses upland vegetation condition in terms of the presence of native vegetation communities. The assumption is that areas with a greater percentage of area with native vegetation communities more closely reflect natural historic conditions than those with a lower percentage. This relatively simple indicator ignores whether or not a native vegetation community is in the "right place" in a historical context. Unfortunately, the low spatial resolution and high level of classification that current potential natural vegetation (PNV) mapping employs make it impossible to address this reliably. It also does not address the condition of vegetation structure in vegetation communities.

\section{Proposition}

Upland portions of a WAA support native vegetation communities.

\section{Data input and truth value}

Percent of a WAA with native vegetation communities land cover. This data input was calculated by intersecting the Composite Land Cover layer with the WAA layer in ArcMap. The resulting database file was exported to an Excel spreadsheet and manipulated with pivot tables and macro tools to create a WAA (rows) by land cover type (columns) matrix. The area of land cover types representing native vegetation communities were summed for each WAA, then divided by the total area of the WAA to determine the percent of a WAA area with native vegetation community land cover 
types. The range of values for this indicator was $0-100$ percent. WAAs with 100 percent native vegetation communities were assigned a truth value of " 1 ," and WAAs with o percent native vegetation communities were assigned a value of "O." Figure 17 shows that a simple linear relationship was assumed between the totally false and totally true endpoints.

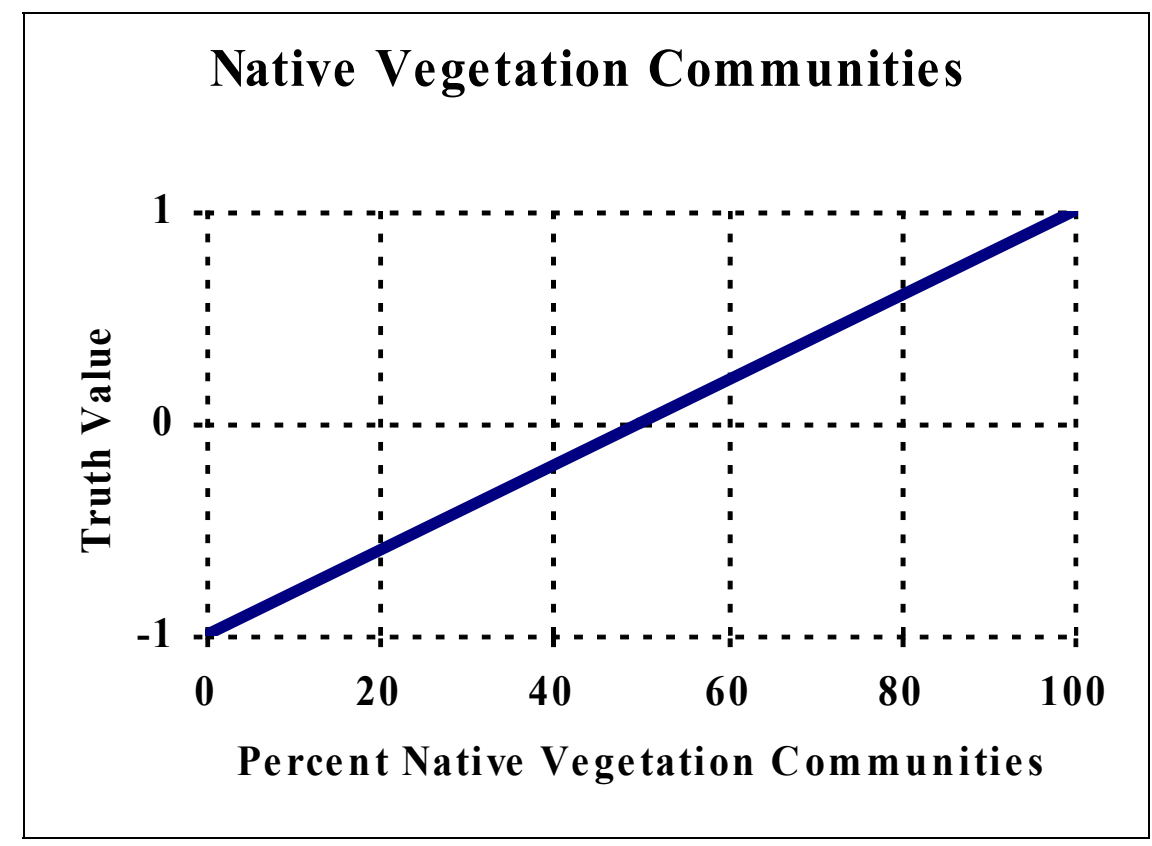

Figure 17. Relationship between truth value and data input for Native Vegetation Communities indicator.

\section{Fire Regime Condition Class (indicator)}

Overview

An FRCC is a standardized, interagency index that measures the departure of current conditions from the natural (historical) range of variability or "reference fire regime" (Hann and Bunnell 2001). Departure from the reference fire regime is a result of changes to one or more of the following ecological components: vegetation characteristics (i.e., species composition, structural stages, stand age, canopy closure, and mosaic pattern); fuel composition; fire frequency, severity, and pattern; and other associated disturbances (such as insect and disease mortality, grazing, and drought) (Schmidt et al. 2002). An FRCC value of "1" indicates conditions within the reference fire regime in terms of vegetation characteristics; fuel composition; fire frequency, severity and pattern; and other associated disturbances. An FRCC value of " 2 " indicates moderate departure from the reference fire regime. An FRCC value of " 3 " indicates a substantial 
departure from the reference fire regime. Note that no FRCC value is normally assigned to "non-wildlands" areas (i.e., agricultural lands, reservoirs, urban areas, roads, etc.). However, for this analysis, an FRCC value of " 4 " is assigned to non-wildland areas.

\section{Proposition}

Uplands in a WAA are within the range of natural historic variability (i.e., reference conditions) with respect to vegetation composition, vegetation structure, fuel composition, fire frequency, severity, and pattern, and other associated disturbances such as insect and disease mortality, grazing, and drought.

\section{Data input and truth value}

Mean FRCC value in a WAA. This data input was calculated using the zonal statistics tool in the ArcMap Spatial Analyst extension. The WAA shapefile was used as the zone dataset and a 100-m pixel FRCC grid file as the value raster. The range of values for this indicator was " 1 " to " 4 ." WAAs with a mean FRCC value of " 1 " were assigned a totally true truth value of "1," and WAA with a mean FRCC value of " 4 " were assigned a totally false truth value of "-1." Figure 18 shows a linear relationship assumed between the totally true and totally false breakpoints.

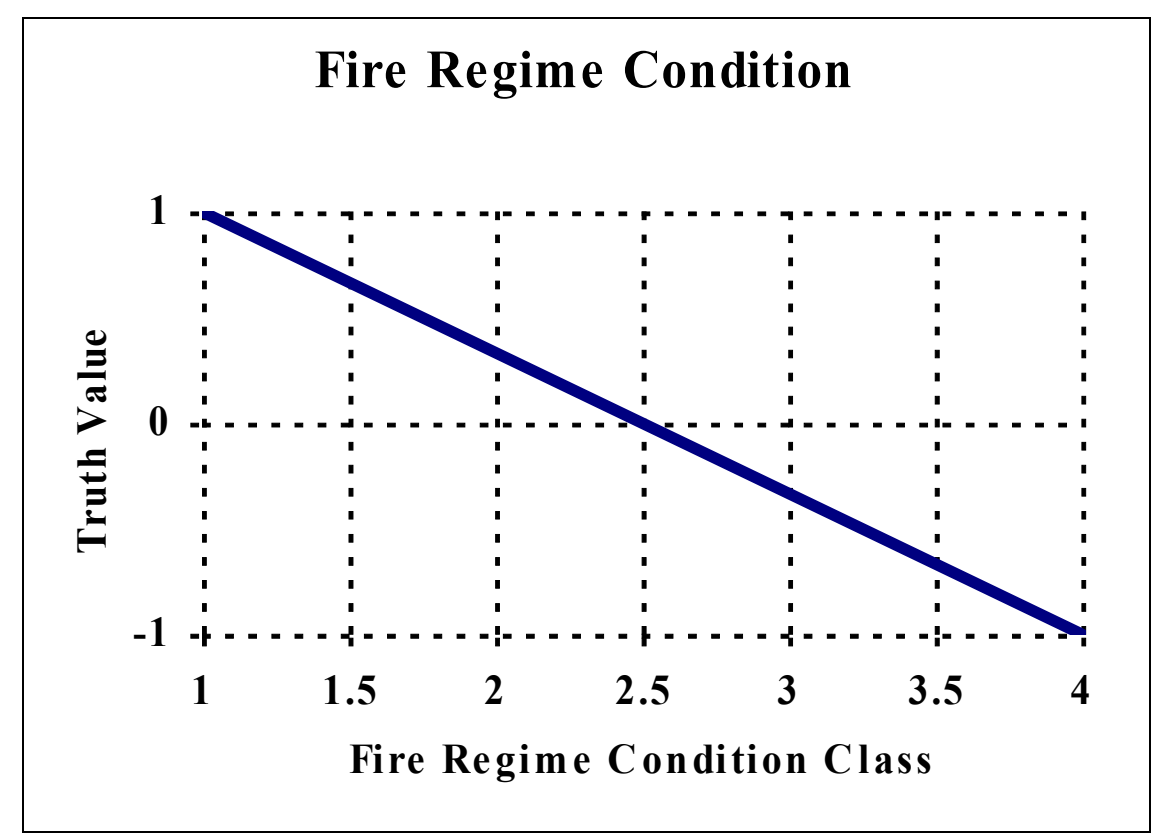

Figure 18. Relationship between truth value and data input for Fire Regime Condition Class indicator. 


\section{Fauna Condition (secondary criterion) - overview}

The Fauna Condition criterion focuses on fauna biodiversity using species richness as the metric to examine the potential versus predicted distribution of terrestrial vertebrates including amphibians, birds, mammals, and reptiles. As with vegetation condition, it is generally not possible to assess the fauna richness across an entire watershed using field-based surveys because such datasets usually do not exist. The alternative is to predict the distribution of fauna based on species range maps and the presence of suitable habitat types in the area of interest.

To assess fauna condition in the Russian River watershed, terrestrial vertebrate species selected for analysis by the California Gap Analysis (see Davis et al. 1998) were used as a starting point. These species were screened for: (1) introduced species, (2) species not related to habitats of the terrestrial surface of the state, i.e., marine mammals, pelagic birds, waterfowl, bats, (3) species that do not breed in the state, and (4) species whose potential range did not include the Russian River watershed. After this screen, 204 species remained, including 15 species of amphibians, 19 species of reptiles, 46 species of mammals, and 125 species of birds.

Using species potential range maps and the predicted distribution maps developed by the California GAP Analysis Project, the potential number of species (based on range maps) was compared to the predicted number of species (based on the GAP predicted distribution maps) that occur in each WAA.

\section{Percent of potential amphibian richness, percent of potential reptile richness, percent of potential mammal richness, percent of potential bird richness (indicators)}

\section{Overview}

These four indicators measure the potential occurrence of particular species groups within a WAA, based on the species habitat suitability score. To calculate this score, the first step is to determine, based on available range maps, which mammal, bird, reptile or amphibian species had the potential to occur in each of the WAAs. The second step is to assign suitability ratings to the habitat types in the land cover map of the watershed based on the vegetation characteristics of tree size and canopy cover. The third step is to determine the weighted average of habitat suitability for 
each species in each WAA. In the Russian River, this was done using the California Wildlife Habitat Relationships database (Airola 1988). The fourth step is to summarize the results of the analysis by summing the weighted average habitat suitability scores in a WAA for all species by group (e.g., amphibians) with the potential to occur in a WAA.

\section{Proposition}

The upland portion of a WAA supports species whose range maps indicate their potential occurrence in the WAA.

\section{Data input and truth value}

Percent of potential species in a group (amphibian, reptile, mammal, bird) predicted to occur in the WAA. This data input was calculated by intersecting the potential range maps for the species group and the predicted occurrence maps developed as part of the California Gap Analysis Project with the WAA shapefile in ArcMap. The number of species predicted to occur in the WAA was divided by the number of species with the potential to occur in the WAA. The result was multiplied by 100 to obtain the percent potential breeding bird richness. The range of values for this indicator was $0-100$ percent. WAAs with 100 percent species group richness were assigned a totally true truth value of " 1 ," and WAAs with o percent potential breeding bird species richness were assigned a totally false truth value of "-1." Figure 19 shows a linear relationship assumed between the totally true and totally false breakpoints.

\section{Human Stressors (secondary criterion)}

\section{General}

Overview

The human stressors criterion measures anthropogenic factors that could degrade the condition of the watershed. It is based on the Landscape Disturbance Intensity Index, road density, impervious surfaces, population density, and residential unit density indicators. 


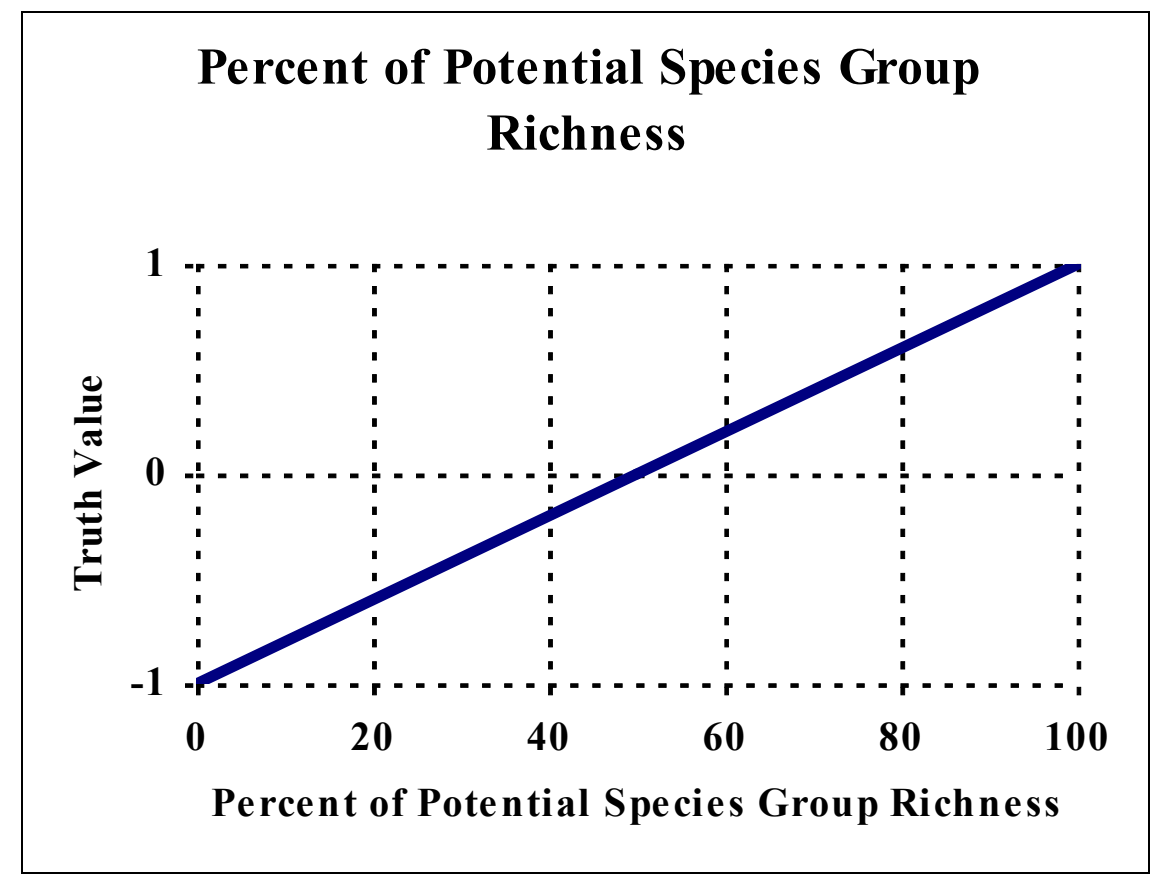

Figure 19. Relationship between truth value and data input for potential species group (amphibian, reptile, mammal, bird) richness indicator.

\section{Proposition}

Human stressors do not occur in upland portions of a WAA.

\section{Landscape Development Intensity (LDI) index (indicator)}

Overview

The condition of ecological communities within a landscape is strongly related to levels of current and historical human activity. The occurrence and intensity of human-dominated land uses can affect adjacent ecological communities through direct, secondary, and cumulative impacts (Brown and Vivas 2005). The Landscape Development Intensity Index (LDI) uses a development-intensity coefficient derived from energy use per unit area to estimate the potential impacts from human-dominated activities experienced by ecological systems in a watershed. The intended use of the LDI is as an index of the human disturbance gradient (i.e., the level of human induced impacts on the biological, chemical, and physical processes of surrounding lands or waters).

\section{Proposition}

LDI Index for upland portions of a WAA is “ 1. " 
Data input and truth value

Average LDI for a WAA. To calculate the average LDI, land uses within a WAA were first assigned an LDI coefficient (Table 2). The average LDI was then calculated for each WAA using the equation:

$$
\mathrm{LDI}_{\text {total }}=\sum \% \mathrm{LU}_{\mathrm{i}}{ }^{*} \mathrm{LDI}_{\mathrm{i}}
$$

where:

$$
\begin{aligned}
\mathrm{LDI}_{\text {total }} & =\mathrm{LDI} \text { value for a WAA } \\
\% \mathrm{LU}_{\mathrm{i}} & =\text { percent of land use "i" in a WAA } \\
\mathrm{LDI}_{\mathrm{i}} & =\text { landscape development intensity coefficient for land use " } \mathrm{i} \text { " }
\end{aligned}
$$

Table 2. LDI coefficients for various land uses.

\begin{tabular}{|l|l|}
\hline Land Use Description & LDI Coefficients ${ }^{1}$ \\
\hline Natural vegetation communities & 1.0 \\
\hline Open water & 1.0 \\
\hline Non-native (ornamental) vegetation plantings & 2.0 \\
\hline Pasture & 3.5 \\
\hline Agriculture & 5.0 \\
\hline Roads (unpaved) & 7.0 \\
\hline Road (paved) & 7.5 \\
\hline Urban & 8.0 \\
\hline
\end{tabular}

1 Extrapolated from Brown and Vivas (2005).

The range of values for this indicator was "1" - "7.6." WAAs with an LDI of " 1 " were assigned a totally true truth value of "1," and WAAs with and LDI of "7.6" were assigned a totally false truth value of "-1." A linear relationship was assumed between the totally true and totally false breakpoints (Figure 20).

\section{Road Area (indicator)}

\section{Overview}

One of the most widespread modifications of the natural landscape during the past century has been the construction and maintenance of roads (Bennett 1991, Noss and Cooperrider 1994). Roads of all kinds affect terrestrial and aquatic ecosystems in seven general ways (Committee on Ecological Impacts of Road Density 2005, Furniss et al. 1991, Trombulak and Frissell 2000): 


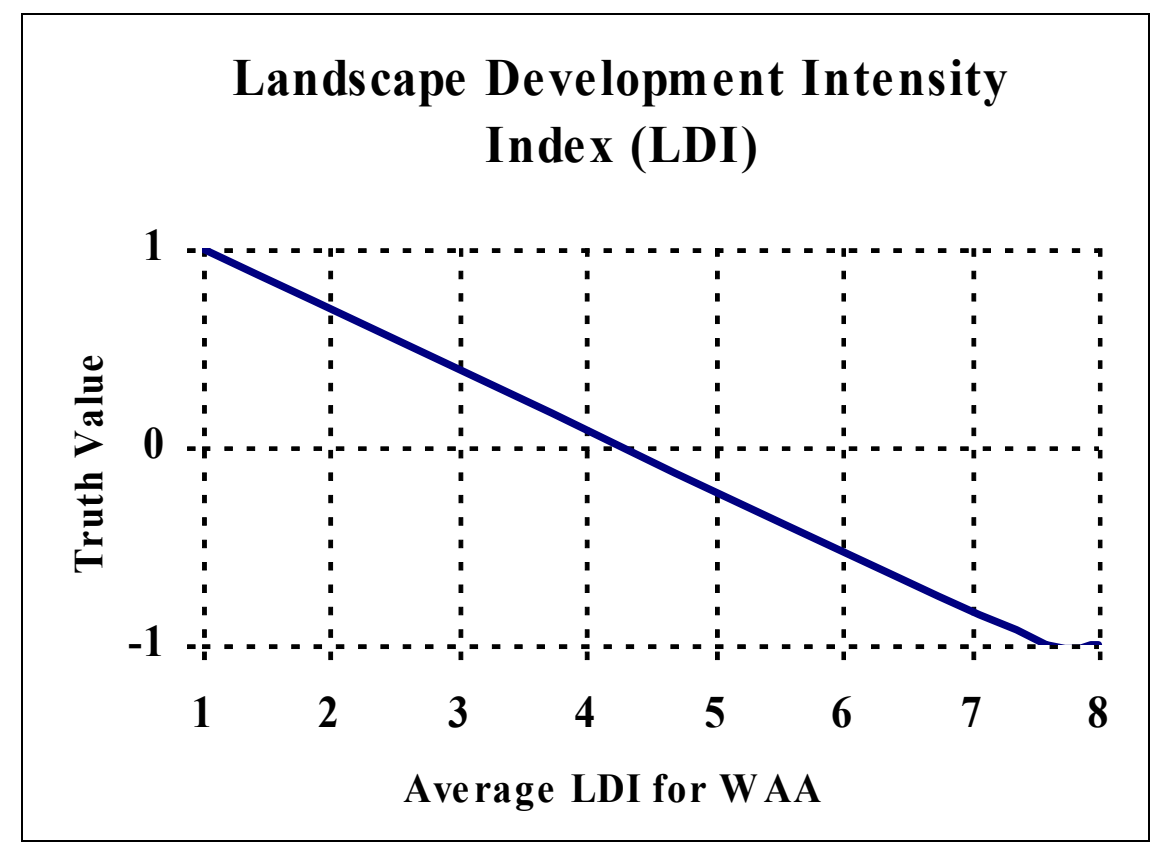

Figure 20. Relationship between truth value and data input for Landscape Development Intensity Index indicator.

1. Increased mortality from road construction

2. Increased mortality from collision with vehicles

3. Modification of animal behavior

4. Alteration of the physical environment

5. Alteration of the chemical environment

6. Spread of exotic species

7. Increased alteration and use of habitats by humans.

\section{Proposition}

Roads do not occur in upland portions of a WAA.

\section{Data input and truth value}

Percent of road area in a WAA. This data input was calculated by intersecting a land cover layer with the WAA layer in ArcMap. The resulting database file was exported to an Excel spreadsheet and manipulated with pivot tables and macros to create a WAA (rows) by land cover type (columns) matrix. The range of values for the Road Area indicator was 0-16.2 percent. Although it can be generally said that increasing road area or density results in increasing modification of upland areas, it is difficult to establish the relationship between road area or density and upland condition for several reasons. First, road area or density has different effects on different components of the ecosystem. For example, 
large mammals are affected when road density exceeds 1 mile per square mile (mi/sq mi) ${ }^{1}$ (van Dyke et al. 1986), whereas salmonids are affected when road density exceeds $2 \mathrm{mi} / \mathrm{sq}$ mi (National Oceanic and Atmospheric Administration (NOAA) 1996), and peak flows increase sharply when road density exceeds $3 \mathrm{mi} / \mathrm{sq} \mathrm{mi}$ (Jones and Grant 1996). Second, most of the guidance in the literature regarding the effect of roads is in terms of road density. Road density is a poor indicator of the effect of roads because the size of the roads is usually not taken into consideration (i.e., narrow, dirt roads and interstate highways are equally weighted). In the Russian River watershed, road area and road density are poorly correlated $(r=0.34)$. Consequently, for this indicator, the $10^{\text {th }}$ and $90^{\text {th }}$ percentile metric values (based on the normalized cumulative distribution function of all WAA metric values) serve as the totally true and totally false breakpoints, respectively. Figure 21 shows a linear relationship assumed between the breakpoints.

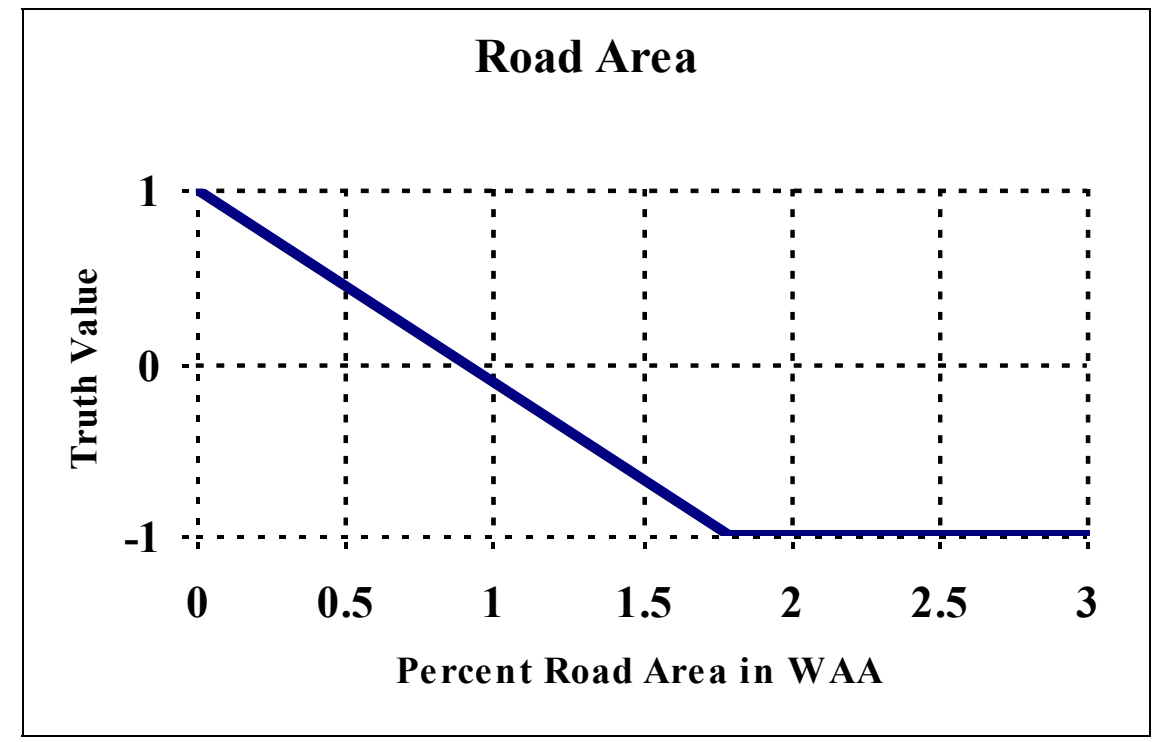

Figure 21. Relationship between truth value and data input for the Road Area indicator.

\section{Impervious Surfaces (indicator)}

\section{Overview}

Perhaps the single most dramatic and pervasive impact of urbanization on watersheds is the replacement of the natural surface with pavement and

\footnotetext{
11 mile (U.S. statute) $=1,609.347$ meters
} 
other water-impervious material such as roads, parking lots, driveways, sidewalks, and rooftops.

Impervious surfaces interrupt the hydrologic cycle, alter stream structure, and degrade the chemical profile of the water that flows to streams. These changes affect fish and wildlife in various ways, and are cumulative within watersheds. Research indicates that when total impervious area in a watershed reaches 10 percent, stream ecosystems begin to show evidence of degradation, and become severe when total impervious area approaches 30 percent. Effects that have been associated with increases in impervious area include an increase in stream temperature, changes in the quantity, duration, timing of stream flow, and increased concentrations of pollutants in streams (Arnold and Gibbons 1996, Booth and Jackson 1997, Schueler 1994, Schueler and Holland 2000).

Proposition

Impervious surfaces resulting from human activities do not occur in upland portions of a WAA.

Data input and truth value

Percent of the WAA that is impervious surface. This data input was calculated using the zonal statistics tool in the ArcMap Spatial Analyst extension. The WAA shapefile was used as the zone dataset and the $30 \mathrm{~m}$ pixel impervious surface grid file as the value raster. The range of metric values for this indicator was $0-48$.o percent. WAAs with o percent unnatural impervious surface were assigned a totally true truth value of "1," and WAAs with 30 percent unnatural impervious surface were assigned a totally false truth value of "-1." The totally false truth value was based on the literature (see above). Figure 22 shows a linear relationship assumed between the totally true and totally false breakpoints.

\section{Population Density (indicator)}

Overview

The condition of ecological communities within a landscape is related to the current and historical levels of human activity (Harrison and Pearce 2001). Population density is a readily available indicator of the degree to which human activities have modified upland areas. Direct, secondary, and cumulative impacts increase with an increase in human population. 


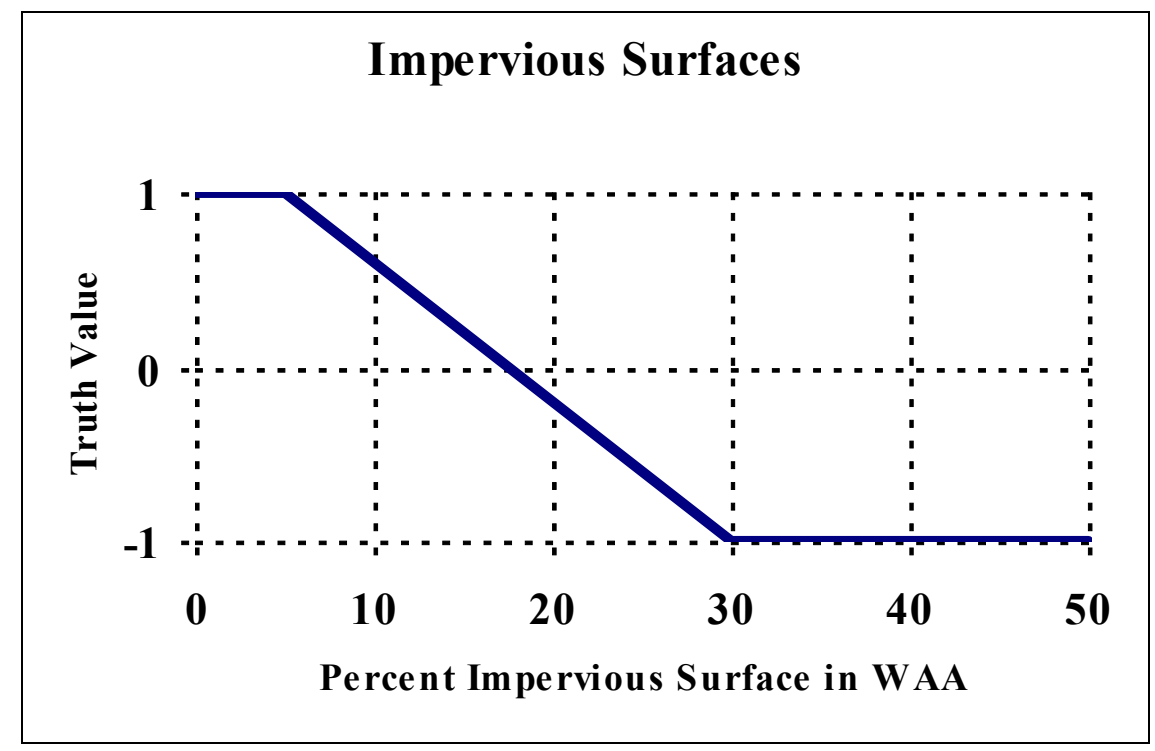

Figure 22. Relationship between truth value and data input for Impervious Surfaces indicator.

\section{Proposition}

Humans do not live in upland portions of a WAA.

\section{Data input and truth value}

Average population per square mile in a WAA, calculated based on 2000 census data. This data input was calculated using the zonal statistics tool in the ArcMap Spatial Analyst extension. The WAA shape file was used as the zone dataset and the 10-m pixel population density grid file as the value raster. The range of values for this indicator was $0-6780$ persons/ sq mi. Although it can be generally said that increasing population density results in increasing modification of upland areas, it is difficult to establish the relationship between population density and upland condition because increasing population density has variable effects on different components of the ecosystem. Consequently, for this indicator, the $10^{\text {th }}$ and $90^{\text {th }}$ percentile metric values, based on the normalized cumulative distribution function of all WAA metric values, serve as the totally true and totally false breakpoints, respectively. Figure 23 shows a linear relationship assumed between the breakpoints. 


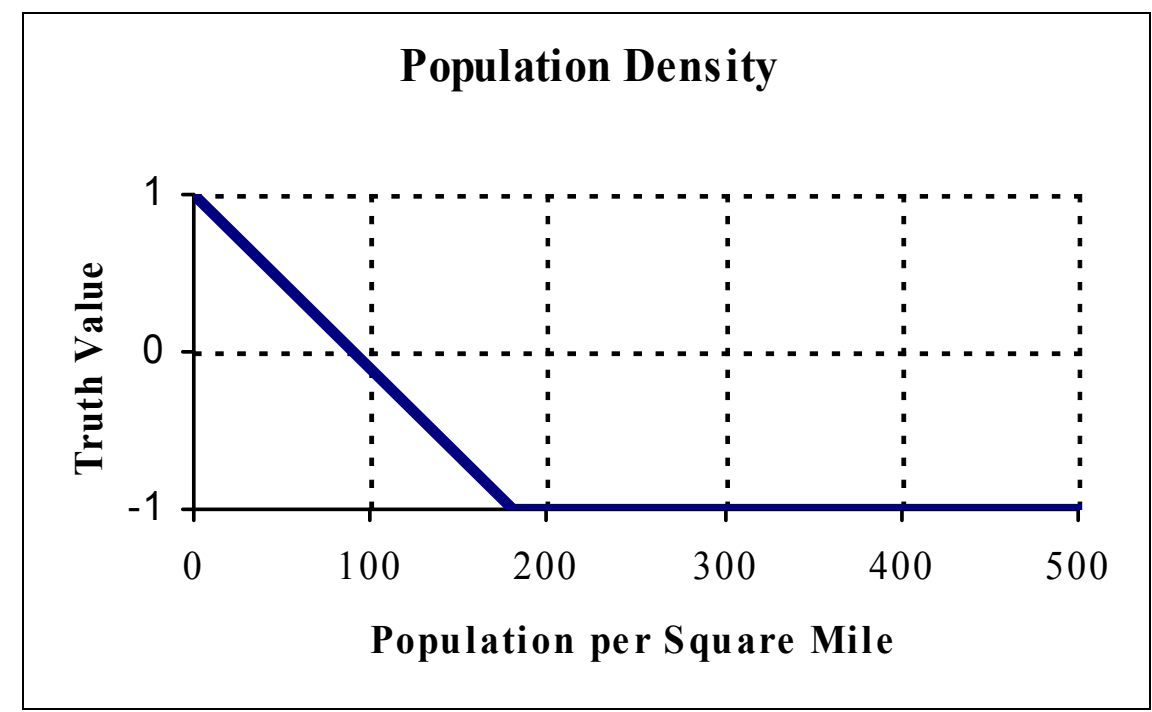

Figure 23. Relationship between truth value and data input for Population Density indicator.

\section{Residential Unit Density (indicator)}

\section{Overview}

The condition of ecological communities within a landscape is related to the current and historical levels of human activity. The density of residential housing units is a readily available indicator of the degree to which human activities have modified upland areas. Direct, secondary, and cumulative impacts increase with an increase in housing unit density.

\section{Proposition}

Residential units do not exist in upland portions of a WAA.

\section{Data input and truth values}

Residential housing units per square mile in a WAA, based on 2000 census data. This data input was calculated using the zonal statistics tool in the ArcMap Spatial Analyst extension. The WAA shape file was used as the zone dataset and the 10-m pixel residential unit density grid file as the value raster. The range of values for this indicator was 1 - $49 \mathrm{units} / \mathrm{sq} \mathrm{mi}$. Although it can be generally said that increasing residential housing unit density results in increasing modification of upland areas, it is difficult to establish the relationship between housing density and upland condition because increasing housing density has variable effects on different components of the ecosystem. Consequently, for this indicator, the $10^{\text {th }}$ and 
$90^{\text {th }}$ percentile metric values, based on the normalized cumulative distribution function of all WAA metric values, serve as the totally true and totally false breakpoints, respectively. Figure 24 shows a linear relationship assumed between the breakpoints.

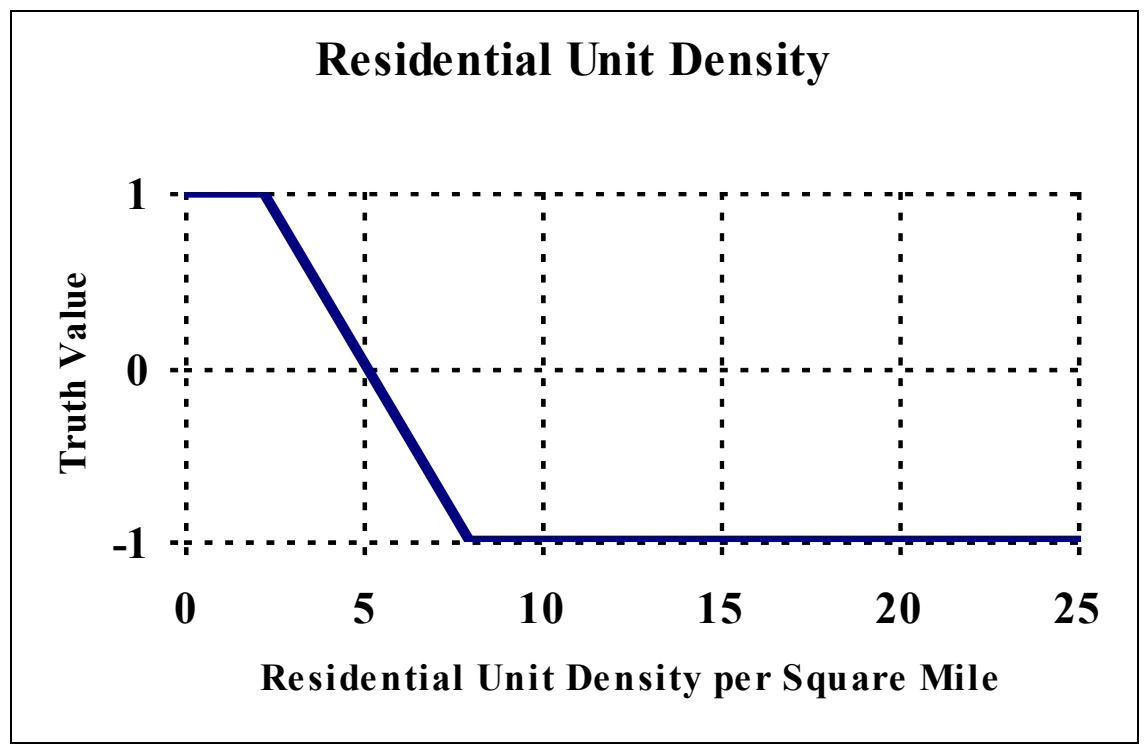

Figure 24. Relationship between truth values and data input for Residential Unit Density indicator. 


\section{Conclusion}

This work has described the application of an updated version of the Multi-Scale Assessment of Watershed Integrity (MAWI) approach, which was developed for use in the Russian River watershed in northern California as an assessment and planning model. It is concluded that it is possible to adapt the Russian River MAWI model for use in watersheds nationally. 


\section{References}

Airola, D. A. 1988. Guide to the California Wildlife Habitat Relationships System. Sacramento, CA: California Department of Fish and Game.

Arnold, C. L., and C. J. Gibbons. 1996. Impervious surface coverage: The emergence of a key environmental indicator. Journal of the American Planning Association 62:243-258.

Bennett, A. F. 1991. Roads, roadsides, and wildlife conservation: A review. In Nature Conservation 2: The Role of Corridors, ed. D. A. Saunders and R. J. Hobbes, 99-118. New South Wales, Australia: Surrey Beatty and Sons, Chipping Norton.

Booth, D. B., and C. R. Jackson. 1997. Urbanization of aquatic systems: Degradation thresholds, stormwater detection, and the limits of mitigation. Journal of the American Water Resources Association 35:1077-1090.

Brown, M. T., and M. B. Vivas. 2005. Landscape development intensity index. Environmental Monitoring and Assessment 101:289-309.

Committee on Ecological Impacts of Road Density. 2005. Assessing and managing the ecological impacts of paved roads. Washington, DC: National Research Council of the National Academies. The National Academies Press.

Davis, F. W., D. M. Stoms, A. D. Hollander, K. A. Thomas, P. A. Stine, D. Odion, M. I. Borchert, J. H. Thorne, M. V. Gray, R. E. Walker, K. Warner, and J. Graae. 1998. The California Gap Analysis Project--Final Report. Santa Barbara, CA: University of California, 255 pp. (http://www.biogeog.ucsb.edu/projects/ gap/gap_rep.html)

Furniss, M. J., T. D. Roelofs, and C. S. Yee. 1991. Road construction and maintenance. American Fisheries Society Special Publication 19:297-323.

Hann, W. J., and D. L. Bunnell. 2001. Fire and land management planning and implementation across multiple scales. International Journal of Wildland Fire 10:389403 .

Harrison, P. and F. Pearce. 2001. AAAS atlas of population and environment. American Association for the Advancement of Science and the University of California Press. 215 pp.

Headquarters, U.S. Army Corps of Engineers (HQUSACE). March 2004. Civil Works Strategic Plan, Fiscal Year 2004 - Fiscal Year 2009. Washington, DC.

Jarvinen, O. 1985. Conservation indices in land use planning: Dim prospects for a panacea. Orins Fennica 62:101-106.

Jones, J. A., and G. E. Grant. 1996. Peak flow responses to clearcutting and roads in small and large basins, Western Cascades, Oregon. Water Resources Research 32:959974. 
National Oceanic and Atmospheric Administration (NOAA). 1996. Coastal salmon conservation: working guidance for comprehensive salmon restoration initiatives on the Pacific Coast.

National Research Council, Committee to Evaluate Indicators for Monitoring Aquatic and Terrestrial Environments. 2000. Ecological indicators for the Nation. Washington, DC: National Academy of Sciences.

Noss, R. F., and A. Y. Cooperrider. 1994. Saving nature's legacy. Island Press, Washington, DC.

Reid, L. M. 1998. Cumulative watershed effects and watershed analysis. In River Ecology and Management: Lessons from the Pacific Coastal Ecoregion, ed. R. J. Naiman, and R. E. Bilby. New York: Springer-Verlag, 476-501.

Reynolds, K. M. 2003. Ecosystem management decision support 3.o. General Technical Report. PNW-GTR-470. Portland, OR: U.S. Forest Service, Pacific Northwest Research Station. http://www.fsl.orst.edu/emds/

Schmidt, K. M., J. P. Menakis, C. C. Hardy, W. J. Hann, and D. L. Bunnell. 2002. Development of coarse-scale spatial data for wildland fire and fuel management. General Technical Report RMRSGTR-87. Fort Collins, CO:

U.S. Department of Agriculture, Forest Service, Rocky Mountain Research Station.

Schueler, T. R. 1994. The importance of imperviousness. Watershed Protection Techniques 1:100-111.

Schueler. T. R. and H. K. Holland, eds. 200o. The practice of watershed protection. Center for Watershed Protection. Ellicott City, MD.

Smith, R. D., C. V. Klimas, and B. A. Kleiss. 2005. A watershed assessment tool for evaluating ecological condition, proposed impacts, and restoration potential at multiple scales. SWWRP Technical Notes Collection, ERDC TN-SWWRP-05-3. Vicksburg, MS: U.S. Army Engineer Research and Development Center.

Strahler, A. N. 1957. Quantitative analysis of watershed geomorphology. Transactions of the American Geophysical Union 38:913-920.

Trombulak, S. C., and C. A. Frissell. 2000. Review of ecological effects of roads on terrestrial and aquatic communities. Conservation Biology 14:18-30.

Van Dyke, F. B., R. H. Brocke, H. G. Shaw, B. B. Ackerman, R. P. Hemker, and F. G. Lindzey. 1986. Reactions of mountain lions to logging and human activity. Journal of Wildlife Management 50:95-102. 


\section{Acronyms and Abbreviations}

\begin{tabular}{ll} 
Term & Spellout \\
\hline AAAS & $\begin{array}{l}\text { American Association for the Advancement of Science } \\
\text { (AAAS) }\end{array}$ \\
ANSI & American National Standards Institute \\
BA & basal area \\
CA & California \\
CO & Colorado \\
DC & direct current \\
EL & Environmental Laboratory \\
EMDS & Ecosystem Management Decision Support System \\
ERDC & Engineer Research and Development Center \\
EL & Environmental Laboratory \\
ESRI & Environmental Systems Research Institute, Inc. \\
FRCC & Fire Regime Condition Class \\
GIS & geographic information system \\
LDI & Landscape Development Intensity \\
MAWI & Multi-Scale Assessment of Watershed Integrity \\
MD & Maryland \\
MS & Mississippi \\
NOAA & National Oceanic and Atmospheric Administration \\
NR & Not Rated \\
NSN & National Supply Number \\
OMB & Office of Management and Budget \\
PNV & percent potential natural vegetation \\
RMSE & Root Mean Square Error \\
SWWRP & System-Wide Water Resources Program \\
& \\
&
\end{tabular}




\begin{tabular}{ll} 
Term & Spellout \\
\hline TBD & to be determined \\
TN & Technical Note \\
TNT & trinitrotoluene \\
TR & Technical Report \\
URL & Universal Resource Locator \\
USACE & U.S. Army Corps of Engineers \\
USDA & U.S. Department of Agriculture \\
USGS & U.S. Geological Survey \\
VA & Virginia \\
WWW & World Wide Web
\end{tabular}




\section{Glossary}

Criteria: The standard on which the watershed is evaluated and judgments or decisions are made. Criteria are composed of additional criteria or indicators. Criteria are evaluated in terms of a proposition.

Data Catalog: A means of organizing data in MAWI.

Data Input: The actual quantitative or qualitative values associated with an indicator.

Drainage Basin: The local drainage basin of a Wetland Assessment Area plus the local drainage basins of all upstream Wetland Assessment Areas.

EMDS: Ecosystem Management and Decision Support. The software used by MAWI to display results from the NetWeaver knowledge base and to run scenarios.

Fuzzy Logic: A form of logic that recognizes varying degrees of truthfulness/falseness of a proposition, rather than just simple true/false values.

Indicator: A factor used to assess criteria, and that has a direct data input.

Knowledge Base: A collection of criteria, indicators, and their relationships to one another.

Local Drainage Basin: Area within a Wetland Assessment Area that drains into its mainstem or tributaries.

Level of Support: The category to which a truth value is assigned within EMDS. The levels of support are: No support, very low, low, undetermined, moderate, strong, and full support.

Missing Data: Data that are needed to evaluate an indicator in the knowledge base, but is unavailable. Indicators with missing data are given a truth value of 1.0.

NetWeaver: The software used by MAWI to create and apply knowledge bases. 
Primary Criterion: The overall proposition that is being evaluated by the knowledge base.

Proposition: A statement for which a truth value is determined. In MAWI, every indicator and criterion is based on a proposition.

Secondary Criteria: Criteria antecedent to the primary criteria in a knowledge base.

Truth Value: A value from -1.0 to 1.0 that is the result of a fuzzy logic operation and reflects the degree of truthfulness/falseness of a proposition. A value of -1.0 means the proposition is completely false, and a value of 1.0 means the proposition is completely true.

Watershed Assessment Area (WAA): A relatively homogenous portion of the watershed that is assessed using criteria. 


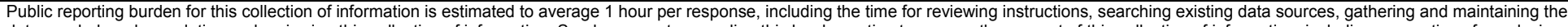

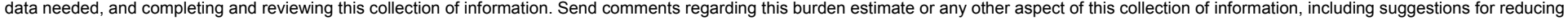

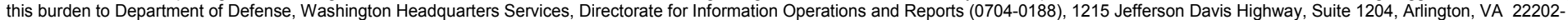

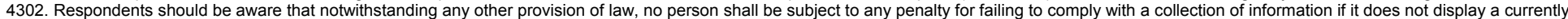
valid OMB control number. PLEASE DO NOT RETURN YOUR FORM TO THE ABOVE ADDRESS.

\begin{tabular}{|l|l|l} 
1. REPORT DATE (DD-MM-YYYY) & 2. REPORT TYPE & 3. DATES COVERED (From - To)
\end{tabular} April 2008 Final report

\section{TITLE AND SUBTITLE}

Using a Multi-Scale Assessment of Watershed Integrity (MAWI) Approach for Establishing Baseline Conditions in Watersheds

5a. CONTRACT NUMBER

5b. GRANT NUMBER

5c. PROGRAM ELEMENT NUMBER

\section{AUTHOR(S)}

Jeff P. Lin, Ronald D. Smith, and Barbara A. Kleiss

5d. PROJECT NUMBER

5e. TASK NUMBER

5f. WORK UNIT NUMBER

\section{PERFORMING ORGANIZATION NAME(S) AND ADDRESS(ES)}

U.S. Army Engineer Research and Development Center Environmental Laboratory

8. PERFORMING ORGANIZATION REPORT NUMBER

3909 Halls Ferry Road

Vicksburg, MS 39180-6199

ERDC/EL TR-08-14

\section{SPONSORING/MONITORING AGENCY NAME(S) AND ADDRESS(ES)}

10. SPONSOR/MONITOR'S ACRONYM(S)

Headquarters, U.S. Army Corps of Engineers

Washington, DC 20314-1000

11. SPONSOR/MONITOR'S REPORT NUMBER(S)

\section{DISTRIBUTION/AVAILABILITY STATEMENT}

Approved for public release; distribution is unlimited.

\section{SUPPLEMENTARY NOTES}

\section{ABSTRACT}

This report describes the development and application of an updated version of the Multi-Scale Assessment of Watershed Integrity (MAWI) approach for watershed assessment. This work demonstrated the approach's capabilities as an assessment and planning tool using parts of the MAWI model developed for the Russian River watershed in northern California. The report also discusses the possibility of adapting the Russian River MAWI model for use in watersheds nationally.

\section{SUBJECT TERMS}

MAWI

Russian River, California
Water resources management

Watershed model

\section{SECURITY CLASSIFICATION OF:}

\begin{tabular}{|l|l|l|}
\hline $\begin{array}{l}\text { a. REPORT } \\
\text { UNCLASSIFIED }\end{array}$ & $\begin{array}{c}\text { b. ABSTRACT } \\
\text { UNCLASSIFIED }\end{array}$ & $\begin{array}{c}\text { c. THIS PAGE } \\
\text { UNCLASSIFIED }\end{array}$ \\
\hline
\end{tabular}

7. LIMITATION OF ABSTRACT
18. NUMBER OF PAGES

60 19a. NAME OF RESPONSIBLE PERSON

19b. TELEPHONE NUMBER (include area code) 